\title{
SEA WATER INTRUSION MODEL OF AMCHITKA ISLAND, ALASKA
}

Prepared by

Stephen W. Wheatcraft

Submitted to

Nevada Operations Office

U.S. Department of Energy

September 1995

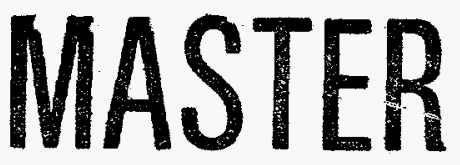

DISTRIBUTION OF THIS DOCUMENT IS UNLATTEL

LM.

Publication \#45127 


\section{DISCLAMMER}

Portions of this document may be illegible in electronic image products. Images are produced from the best available original document. 
This report was prepared as an account of work sponsored by the United States Government. Neither the United States nor the United States Department of Energy, nor any of their employees, makes any warranty, express or implied, or assumes any legal liability or responsibility for the accuracy, completeness or usefulness of any information, apparatus, product or process disclosed, or represents that its use would not infringe privately owned rights. Reference herein to any specific commercial product, process, or service by trade name, mark, manufacturer, or otherwise, does not necessarily constitute or imply its endorsement, recommendation, or favoring by the United States Government or any agency thereof. The views and opinions of authors expressed herein do not necessarily state or reflect those of the United States Government or any agency thereof.

This report has been reproduced directly from the best available copy.

Available to DOE and DOE contractors from the Office of Scientific and Technical Information, P.O. Box 62, Oak Ridge, TN 37831; prices available from (615) 576-8401.

Available to the public from the National Technical Information Service, U.S. Department of Commerce, 5285 Port Royal Rd., Springfield, VA 22161. 


\title{
SEA WATER INTRUSION MODEL OF AMCHITKA ISLAND, ALASKA
}

\author{
prepared by \\ Stephen W. Wheatcraft \\ Hydrology/Hydrogeology Department \\ Environmental and Resource Sciences \\ University of Nevada, Reno \\ Reno, Nevada 89557
}

Publication No. 45127

submitted to

Nevada Operations Office

U.S. Department of Energy

Las Vegas, Nevada

September 1995

The work upon which this report is based was supported by the U.S. Department of Energy under Contract \#DOE-UNR-9401. 


\section{CONTENTS}

FIGURES $\ldots \ldots \ldots \ldots \ldots \ldots \ldots \ldots \ldots \ldots \ldots \ldots \ldots \ldots \ldots \ldots \ldots \ldots \ldots \ldots$

TABLES $\ldots \ldots \ldots \ldots \ldots \ldots \ldots \ldots \ldots \ldots \ldots \ldots \ldots \ldots \ldots \ldots \ldots \ldots \ldots \ldots \ldots$

INTRODUCTION $\ldots \ldots \ldots \ldots \ldots \ldots \ldots \ldots \ldots \ldots \ldots \ldots \ldots \ldots \ldots \ldots$

PURPOSE AND SCOPE $\ldots \ldots \ldots \ldots \ldots \ldots \ldots \ldots \ldots \ldots \ldots \ldots \ldots \ldots$

BACKGROUND . . . . . . . . . . . . . . . . . . . . . . . 2

QUANTITATIVE ANALYSIS OF SALT WATER INTRUSION $\ldots \ldots \ldots \ldots \ldots .4$

Immiscible Flow Models $\ldots \ldots \ldots \ldots \ldots \ldots \ldots \ldots \ldots \ldots$

Miscible Flow Models: Density-Coupled Fluid Flow and Solute Transport . . 5

PREVIOUS STUDIES OF SALT WATER INTRUSION $\ldots \ldots \ldots \ldots \ldots \ldots \ldots \ldots$

GEOLOGY OF AMCHITKA ISLAND $\ldots \ldots \ldots \ldots \ldots \ldots \ldots \ldots \ldots \ldots \ldots$

AMCHITKA ISLAND CONCEPTUAL MODEL, GEOMETRY

AND BOUNDARY CONDITIONS $\ldots \ldots \ldots \ldots \ldots \ldots \ldots \ldots \ldots \ldots \ldots$



CHOICE OF MODEL PARAMETER VALUES $\ldots \ldots \ldots \ldots \ldots \ldots \ldots \ldots \ldots$

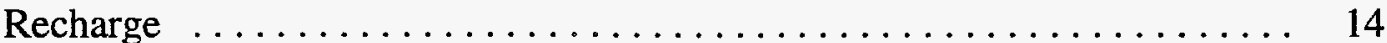

Hydraulic Conductivity $\ldots \ldots \ldots \ldots \ldots \ldots \ldots \ldots \ldots \ldots \ldots \ldots \ldots$

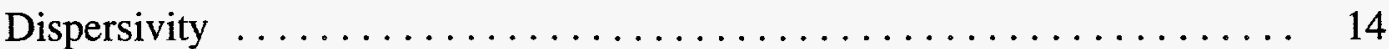

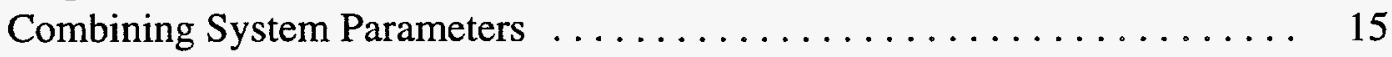

CHOICE OF NUMERICAL CODE AND COMPUTERS $\ldots \ldots \ldots \ldots \ldots \ldots \ldots \ldots$

NUMERICAL CONSIDERATIONS $\ldots \ldots \ldots \ldots \ldots \ldots \ldots \ldots \ldots \ldots \ldots$

FIRST SET OF SIMULATIONS $\ldots \ldots \ldots \ldots \ldots \ldots \ldots \ldots \ldots \ldots \ldots \ldots \ldots \ldots$

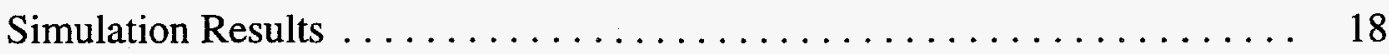

SECOND SET OF SIMULATIONS $\ldots \ldots \ldots \ldots \ldots \ldots \ldots \ldots \ldots \ldots \ldots \ldots$

Simulation Results ................................. 19

TRAVEL TIMES (RESIDENCE TIMES) FOR THE MODELED SYSTEM $\ldots \ldots \quad 28$

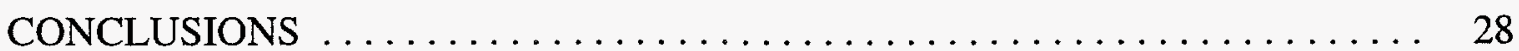

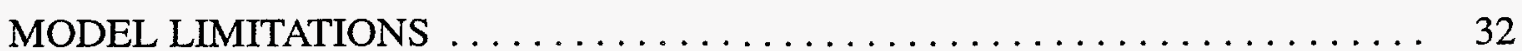

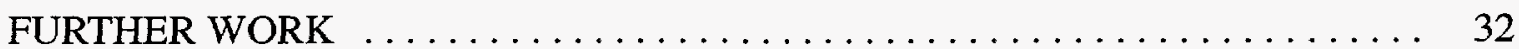

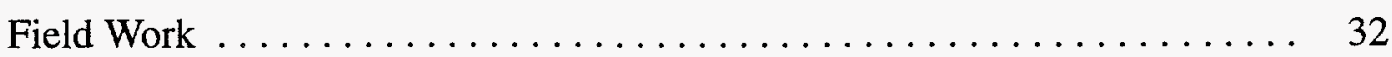

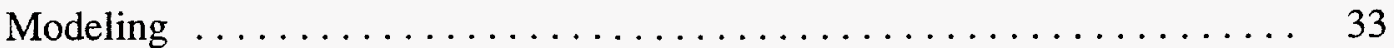

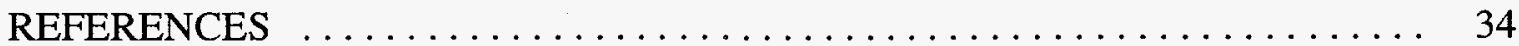

APPENDIX A $\begin{aligned} & \text { Salinity Distributions for } 11 \text { Simulations Varying the } \\ & \text { Hydraulic Conductivity. } \ldots \ldots \ldots \ldots \ldots \ldots \ldots \ldots \ldots \ldots \ldots \ldots \ldots \ldots\end{aligned}$ 


\section{FIGURES}

1. Location of Amchitka Island. $\ldots \ldots \ldots \ldots \ldots \ldots \ldots \ldots \ldots \ldots \ldots \ldots, \ldots \ldots \ldots$

2. Occurrence of salt water intrusion in coastal and island aquifers........ 3

3. The Ghyben-Herzberg relationship. $\ldots \ldots \ldots \ldots \ldots \ldots \ldots \ldots \ldots \ldots \ldots$

4. Schematic cross section of Amchitka (A-A'). . . . . . . . . . 12

5. Model cross section with geometry and boundary conditions. ........ 13

6. Steady-state salinity distribution: $a_{L}=33.3 \mathrm{~m} . \ldots \ldots \ldots \ldots \ldots \ldots \ldots$

7. Steady-state salinity distribution: $a_{L}=66.7 \mathrm{~m} \ldots \ldots \ldots \ldots \ldots \ldots \ldots \ldots$

8. Steady-state salinity distribution: $a_{L}=133 \mathrm{~m} \ldots \ldots \ldots \ldots \ldots \ldots \ldots, 22$

9. Steady-state salinity distributions with velocity vectors: $a_{L}=66.7 \mathrm{~m} \ldots \ldots 24$

10. Steady-state salinity distributions with velocity vectors: $a_{L}=133 \mathrm{~m} . \ldots \ldots 25$

11. Steady-state head distribution for the best-fit set of parameters. . . . . . 26

12. Uniformly distributed streaklines for the best-fit set of parameters. $\ldots \ldots \quad 27$

13. Streaklines placed on three sides to show relative velocities. . . . . . . . 29

14. Streaklines for 500 year travel time for fresh water recharge source. . . . . 30

15. Streaklines for particles originating above and in the Long Shot working point.

\section{TABLE}

1. Parameter Values for First Set of Simulations $\ldots \ldots \ldots \ldots \ldots \ldots \ldots \ldots, 18$ 


\section{INTRODUCTION}

During the 1960s and 1970s, Amchitka Island, Alaska, was the site of three underground nuclear tests, referred to as Milrow, Long Shot and Cannikin. Amchitka Island is located in the western part of the Aleutian Island chain, Alaska, as shown in Figure 1. The island is approximately $56 \mathrm{~km}$ long and ranges from 3.2 to $8 \mathrm{~km}$ wide. At its mid-point, it is approximately $4 \mathrm{~km}$ wide.

The groundwater systems affected by the three underground nuclear tests at Amchitka Island are essentially unmonitored because all of the current monitoring wells are too shallow and not appropriately placed to detect migration from the cavities. The dynamics of the island's fresh water-sea water hydrologic system will control contaminant migration from the three event cavities, with migration expected in the direction of the Bering Sea from Long Shot and Cannikin and the Pacific Ocean from Milrow. The hydrogeologic setting (actively flowing groundwater system to maintain a freshwater lens) suggests a significant possibility for relatively rapid contaminant

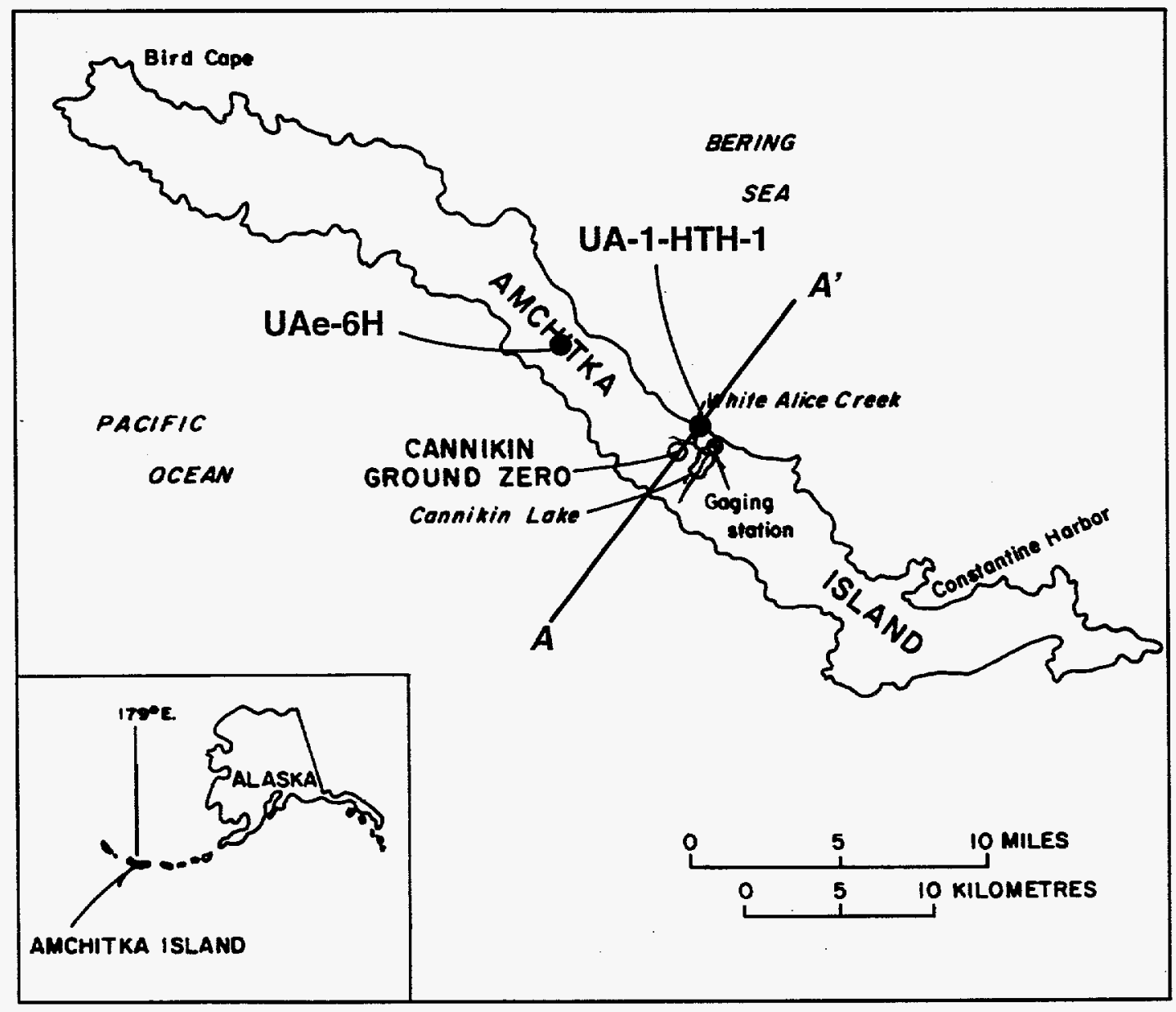

Figure 1. Location of Amchitka Island. 
migration from these sites, but also presents an opportunity to use projected flowpaths to a monitoring advantage.

\section{PURPOSE AND SCOPE}

The purpose of this investigation is to develop a conceptual model of the Amchitka groundwater system and to produce computer model simulations that reflect the boundary conditions and hydraulic properties of the groundwater system. The simulations will be used to assess the validity of the proposed conceptual model and highlight the uncertainties in hydraulic properties of the aquifer. The uncertainties will be quantified by sensitivity analyses on various model parameters. Within the limitations of the conceptual model and the computer simulations, conclusions will be drawn regarding potential radionuclide migration from the three underground nuclear tests.

\section{BACKGROUND}

The Amchitka groundwater system is characterized by the presence of a fresh water lens, transition zone and basal salt water. Gard and Hale (1964) report that the fresh water lens is about $1200 \mathrm{~m}$ thick in the center of the island. The thickness of the fresh water lens and the transition zone is controlled primarily by the recharge rate from precipitation and the hydraulic and dispersive characteristics of the aquifer. Because the transition zone will be relatively thick, it is most appropriate to treat the system as a density-coupled flow and transport problem. The dissolved solutes present in sea water are treated together as one solute, total dissolved solids. The solutions to the flow equation and the advection-dispersion equation are coupled and must be solved simultaneously. This general class of problems is generally referred to as sea water intrusion.

The study of sea water intrusion into coastal aquifers has been an important area of research in hydrology since the late 19th century when Badon-Ghyben (1889) and Herzberg (1901) independently developed an equation that describes the hydrostatic balance between a fresh water lens floating on top of salt water in hydrologic connection with the ocean. Sea water intrusion can occur in any aquifer that is in hydrologic connection with the ocean, and tends to be an important problem in areas where the natural balance between inland recharge and the hydrostatic pressure of salt water has been disturbed by pumping fresh water from the aquifer.

The occurrence of sea water in coastal aquifers can be visualized with a simplified conceptual model (Figure 2). The essential elements are: fresh water recharge from inland sources, sea water intrusion from the ocean side, and an interface or transition zone between the two types of water. The transition zone is a zone of mixing between fresh water and salt water. Under equilibrium conditions, the interface will remain fixed, and fresh water will discharge along the seepage face. Examples of 
(a)

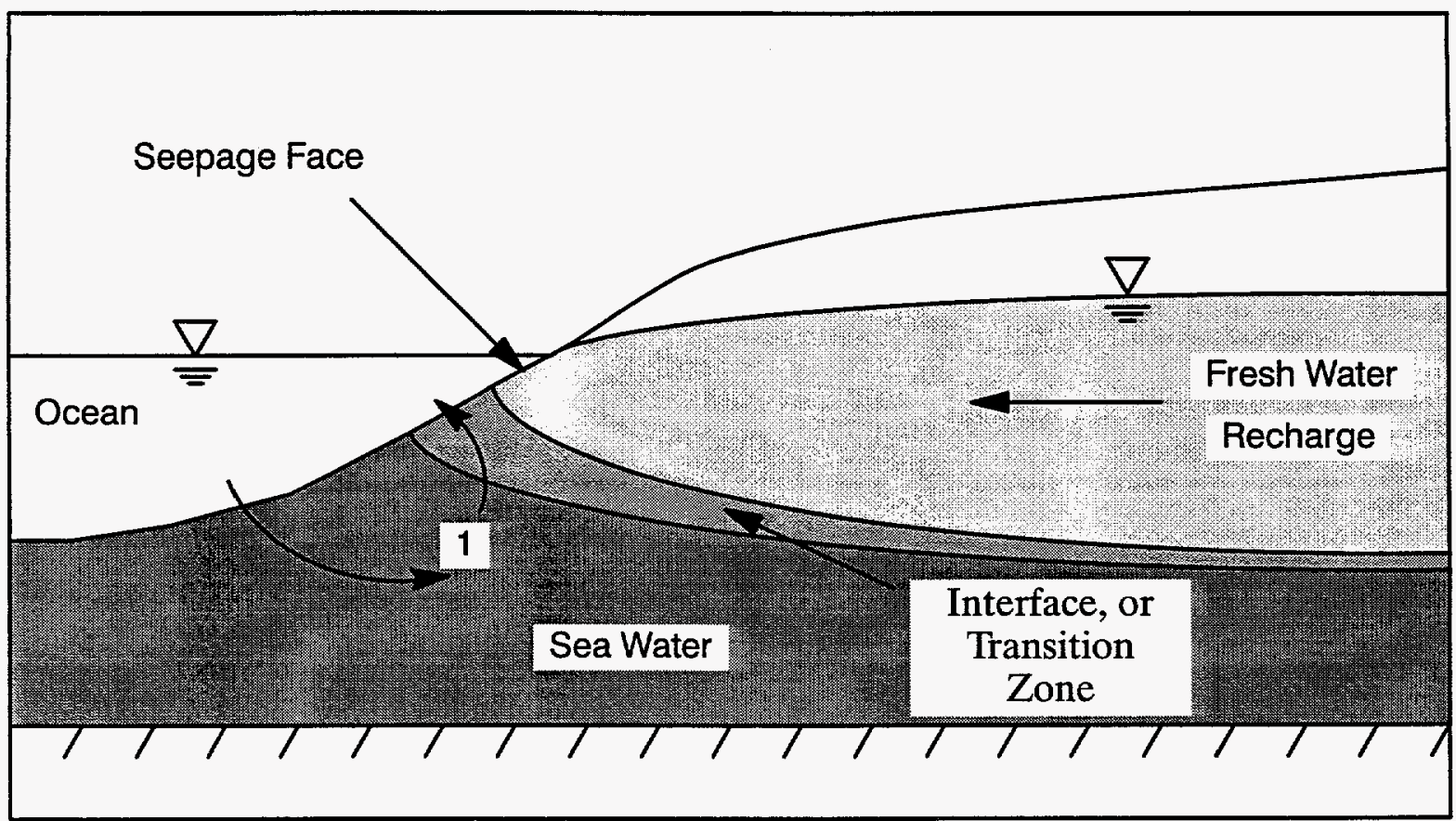

${ }^{1}$ Recirculation of sea water

(b)

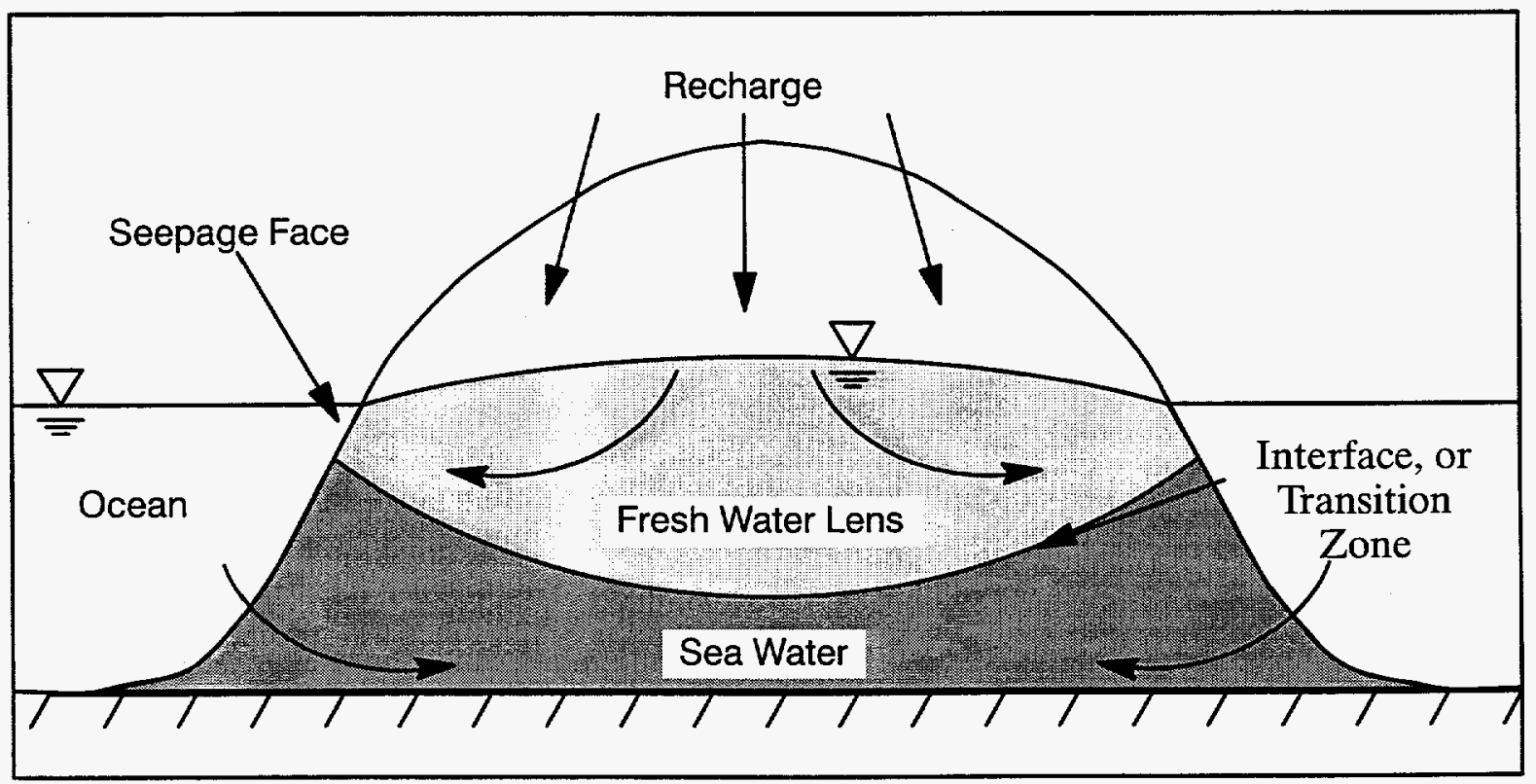

Figure 2. Occurrence of salt water intrusion in coastal and island aquifers. 
site-specific studies of sea water intrusion include the Nile Delta in Egypt (Kashef, 1983), Florida (Andersen et al., 1988), Israel (Mercado, 1985), and Micronesia (Ayers and Vacher, 1986). A conceptual model of an island aquifer intruded with sea water is shown in Figure $2 \mathrm{~b}$. In a coastal aquifer, recharge is predominantly due to lateral inflow, whereas in an island aquifer, it is due to vertical recharge. The conceptual models in Figure 2 are analyzed in different ways. Coastal aquifers (Figure 2a) are usually modeled in the vertical plane. Island systems (Figure $2 b$ ) are also analyzed in the vertical plane when the thickness of the fresh water lens is a significant fraction of the horizontal width of the lens, a situation common in atoll islands. When the lens thickness is small compared to its horizontal extent, the system is often treated in the areal plane.

\section{QUANTITATIVE ANALYSIS OF SALT WATER INTRUSION}

\section{Immiscible Flow Models}

Quantitative treatments of salt water intrusion fall into two broad categories: immiscible and miscible flow. If the transition zone is thin relative to the thickness of the fresh water lens and it is immobile, then it is usually assumed that fresh water and salt water do not mix (immiscible), and the transition zone is considered to be a sharp interface. There are many methods for dealing with sea water intrusion as a two-phase, immiscible flow problem. Under dynamic conditions, or in cases where the fresh water lens is relatively thin compared to the transition zone, miscible flow methods are normally used to quantify the problem. Note that the immiscible approach is just a convenient approximation, as salt water and fresh water are always miscible and any perturbation of the system is likely to cause mixing between the two types of water. Once we think of the problem as being miscible, the system is treated as single phase, with a variable density due to salt concentration. The salt is usually thought of as a single component chemical species because the relative concentrations of constituent ions are assumed to be constant.

The simplest way to model a fresh water lens is to assume that the fresh water, interface and underlying salt water are in hydrostatic equilibrium. This assumption is known as the Ghyben-Herzberg relationship, shown in Figure 3. At $z=0$, under conditions of hydrostatic equilibrium, the pressure at $\mathrm{A}$ must equal the pressure at $\mathrm{B}$. As a consequence:

$$
\mathrm{h}_{\mathrm{s}}=\frac{\rho_{\mathrm{f}}}{\rho_{\mathrm{s}}-\rho_{\mathrm{f}}} \mathrm{h}_{\mathrm{f}} \approx 40 \mathrm{~h}_{\mathrm{f}}
$$

The Ghyben-Herzberg relationship is useful primarily as a rule of thumb for obtaining an estimate of fresh water lens thickness from the height of the water table above sea level. A more realistic approach was illustrated by Glover (1959), in which the fresh water lens is assumed to be in equilibrium between recharge and fresh water discharge to the ocean. Thus, the fresh water is dynamic, but the interface and the underlying salt water are static. The model is an improvement over 


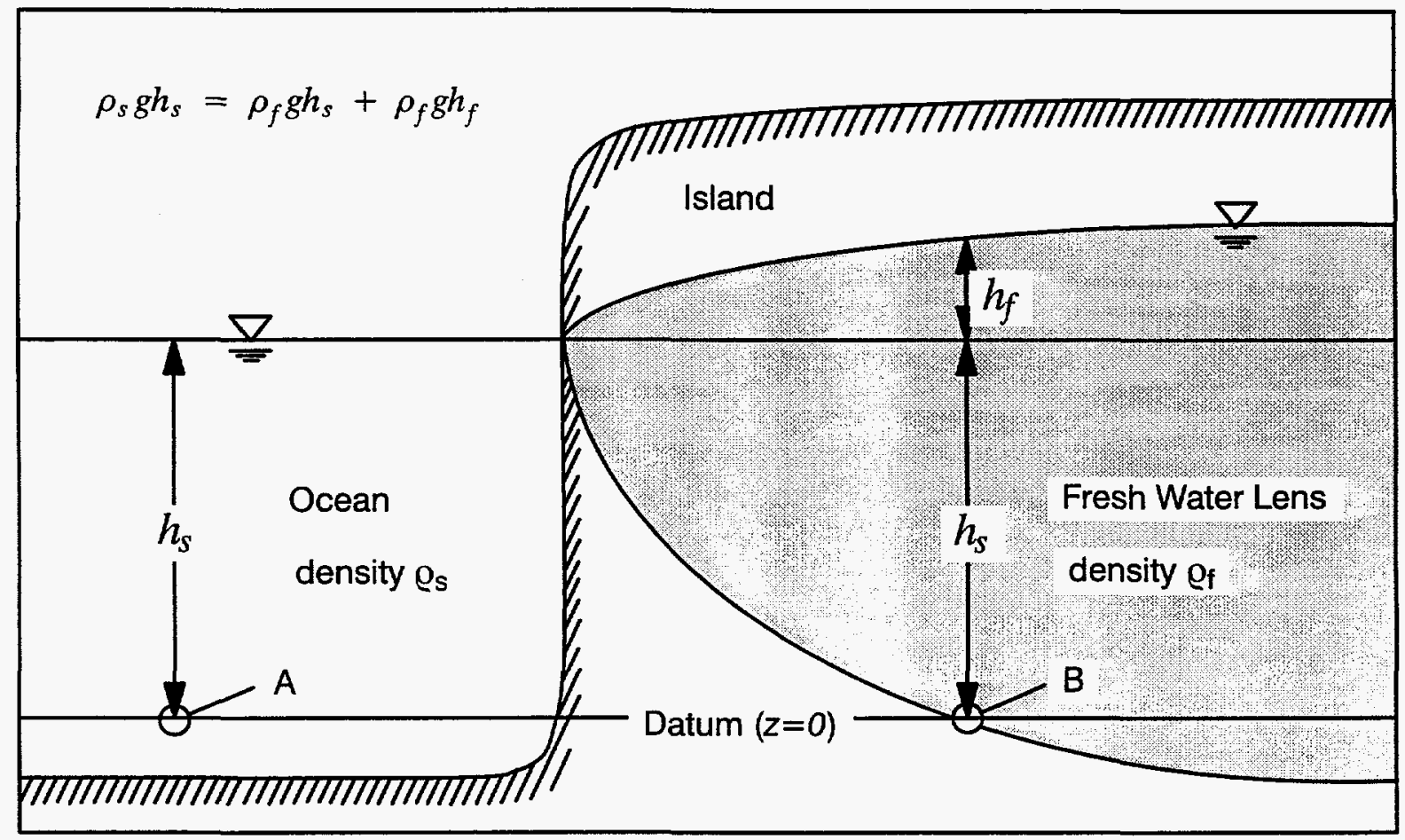

Figure 3. The Ghyben-Herzberg relationship.

the simple hydrostatic Ghyben-Herzberg relationship in that it allows fresh water from recharge to escape to the ocean.

If fresh water is being discharged through pumping, and/or if the interface is disturbed by tidal mixing (Wheatcraft and Buddemeier, 1981), then it is necessary to consider both the fresh water and the salt water to be mobile. If the problem is treated as immiscible, then the solution that one seeks is the position and shape of the interface as a function of time. This problem is non-linear, and very few analytical solutions have been developed. Moreover, if the interface is in motion due to pumping or tidal stresses, then it is likely that enough mixing will take place around the interface so that the assumption of immiscible flow is no longer valid. For such cases, it is necessary to treat the problem as miscible in which salt is in high enough concentration to affect the density of the water. We refer to this problem as the density-coupled fluid flow and solute transport problem, and this is how the Amchitka groundwater system was modeled in this report.

\section{Miscible Flow Models: Density-Coupled Fluid Flow and Solute Transport}

This problem is traditionally formulated using four dependent variables: $\overrightarrow{\mathrm{V}}, \mathrm{P}, \rho$ and $\mathrm{C}$; the fluid velocity, pressure, density and solute concentration, respectively. The four governing equations for these dependent variables are (Wheatcraft and Peterson, 1979) 
Darcy's Law:

$$
\overrightarrow{\mathbf{V}}=-\frac{\overrightarrow{\overrightarrow{\mathbf{k}}}}{\mu}(\nabla P+\rho \mathrm{g} \nabla \cdot \mathbf{Z})
$$

Conservation of Fluid Mass:

$$
\nabla \cdot(\rho \overrightarrow{\mathbf{V}})=-\frac{\partial \rho}{\partial t}
$$

Equation of State:

$$
\rho=\rho_{\mathrm{f}}+\beta_{\mathrm{C}}\left(\mathrm{C}-\mathrm{C}_{\mathrm{f}}\right)
$$

Advection-Dispersion Equation:

$$
\nabla \cdot \mathrm{C} \overrightarrow{\mathbf{V}}-\nabla \cdot(\overrightarrow{\overrightarrow{\mathbf{D}}} \cdot \nabla \mathrm{C})=-\mathrm{n} \frac{\partial \mathrm{C}}{\partial \mathrm{t}}
$$

where:

$$
\begin{aligned}
& \overrightarrow{\overrightarrow{\mathbf{k}}} \equiv \text { intrinsic permeability }\left(\mathrm{L}^{2}\right) \\
& \mathrm{g} \equiv \text { gravitational acceleration }\left(\mathrm{LT}^{-2}\right) \\
& \mathbf{Z} \equiv \text { vertical coordinate axis }(\mathrm{L}) \\
& \rho_{\mathrm{f}} \equiv \text { density of fresh water }\left(\mathrm{ML}^{-3}\right) \\
& \beta_{\mathrm{C}} \equiv \text { coefficient of density variability (constant) }\left(\mathrm{M}^{-1} \mathrm{~L}^{3}\right) \\
& \mathrm{C}_{\mathrm{f}} \equiv \text { concentration of salt in fresh water }\left(\mathrm{ML}^{-3}\right) \\
& \overrightarrow{\overrightarrow{\mathbf{D}}}=\text { coefficient of hydrodynamic dispersion }\left(\mathrm{L}^{2} \mathrm{~T}^{-1}\right) \\
& \mathrm{n}=\text { porosity (dimensionless) } \\
& \mathrm{t}=\text { time }(\mathrm{T}) \\
& \nabla=\text { gradient operator }\left(\mathrm{L}^{-1}\right)
\end{aligned}
$$

The coefficient of hydrodynamic dispersion, $\overrightarrow{\overrightarrow{\mathbf{D}}}$, is a second rank tensor given by (in Einstein's summation notation):

$$
D_{i j}=a_{i j k m} \frac{V_{k} V_{m}}{\bar{V}}
$$

where $\bar{V} \equiv$ the magnitude of the velocity vector. In a homogeneous isotropic porous medium, $a_{i j k m}$ reduces to (Bear 1979): 


$$
\left.\begin{array}{l}
a_{i i i i}=a_{L} \\
a_{i j i j}=a_{T} \\
a_{i j i j}=a_{i j j i}=\frac{1}{2}\left(a_{L}-a_{T}\right)
\end{array}\right\} \quad i \neq j \quad \text { (all other components zero) }
$$

where $a_{L}=$ longitudinal dispersivity $(\mathrm{L})$ and $a_{T}=$ transverse dispersivity (L).

To arrive at the form of the advection-dispersion equation given by equation (5), it is necessary to specify a constitutive relationship of the form:

$$
C \overrightarrow{\mathbf{V}}_{\mathrm{C}}=\mathrm{C} \overrightarrow{\mathbf{V}}-\overrightarrow{\overrightarrow{\mathbf{D}}} \cdot \nabla \mathrm{C}
$$

Equation (8) says that the total flux of solute, $C \overrightarrow{\mathbf{v}}_{\mathbf{C}}$, is the sum of the advective flux, $\mathbf{C} \overrightarrow{\mathbf{v}}$, and the dispersive flux, $\overrightarrow{\overrightarrow{\mathbf{D}}} \cdot \nabla \mathrm{C}$. The dispersive flux term $(\overrightarrow{\overrightarrow{\mathbf{D}}} \cdot \nabla \mathrm{C})$ assumes that the dispersive flux is proportional to the concentration gradient $(\nabla C)$, with the proportionality "constant" being the dispersion coefficient, $\overrightarrow{\overrightarrow{\mathbf{D}}}$. This assumption is commonly known as the Fickian (or Gaussian) model of dispersion.

Traditional deterministic approaches to modeling solute transport treat the dispersivities as constant values (Fickian approach). The selection of appropriate values for dispersivity at the field scale is one of the most difficult parts of the modeling process, and deserves some elaboration. The justification for the Fickian model of dispersion arises from the assumption that dispersion is a larger-scale analogy of molecular diffusion (Fick's Law). The Fickian model for dispersion was shown to be appropriate for laboratory-scale transport in homogeneous, isotropic porous media by Bear (1961) for an ideal tracer, e.g., for a solute which is non-reactive and does not affect the density of the fluid. The Fickian dispersion model implies that the longitudinal and transverse dispersivities, $a_{L}$ and $a_{T}$, are constant, intrinsic properties of the porous medium. The appropriateness of this model was called into question by a series of experiments at the Borden field site (Sudicky and Cherry, 1979; Sudicky et al., 1983; Mackay et al., 1986). In these field experiments, values of dispersivity were calculated based on laboratory and natural gradient tracer tests in the field. Then the tracer tests were allowed to continue and the field experiment results were compared with predictions based on the dispersivity values calculated from laboratory and natural gradient field tracer tests. In these tracer tests, as well as a number of others, it was found that the dispersivity values had to be increased in the models to get model predictions to agree with field tracer test results.

The explanation for this well known scale effect in dispersivity is that spatial variability at the field scale leads to non-Fickian dispersion. Field-scale dispersion is caused predominantly by differential advection resulting from the statistical distribution of the hydraulic conductivity. 
Dispersivity values have been found to increase with scale over a wide range of scales (Gelhar, 1986). New field-scale theories of solute transport have been developed which account for this non-Fickian dispersion for aquifers by assuming that the variations in hydraulic conductivity can be described as a stationary, lognormally distributed random variable. These theories are generally known as stochastic theories (Gelhar, 1986; Dagan, 1986).

Some recent studies have focused on the effects of porous medium heterogeneity to develop stochastic models of the macrodispersion process for the salt water intrusion problem (Welty et al., 1989; Welty and Gelhar, 1991, 1992). The spectral stochastic approach used to develop this model starts with the assumption that at a local scale, i.e., a scale smaller than the correlation scale of the hydraulic conductivity, the traditional deterministic governing equations are correct. If the governing equations are wrong at a local scale, then the stochastic models will include the same inaccuracies. In addition, macrodispersion is caused primarily by differential advection of a solute mass that is moving with the natural gradient. The transition zone between salt water and fresh water is usually not moving with a natural gradient, but is instead relatively localized with respect to mean position. As a result, molecular diffusion processes become relatively much more important when compared to the traditional analysis of a solute plume being transported with the mean flow.

It is apparent from this discussion that the selection of appropriate dispersivity values for Amchitka (or any other field site) is anything but straightforward. In this study, we use the deterministic approach, selecting constant values for dispersivity. In addition to the above arguments, there are additional criteria related to model discretization that must be considered when choosing dispersivity values. These criteria are discussed in the section entitled "Choice of Model Parameter Values."

\section{PREVIOUS STUDIES OF SALT WATER INTRUSION}

In this section, we shall review the relevant literature that pertains to the density-coupled fluid flow and solute transport problem as it relates to salt water intrusion. Numerous studies have been conducted treating the problem as if it were a two-phase immiscible flow problem (e.g., Bear and Todd, 1960; Bear and Dagan, 1962). Because our interest is in treating the salt water and fresh water as miscible, we will not discuss the immiscible studies further. See Reilly and Goodman (1985) for a thorough review of these studies. The first attempt to treat the problem as fully miscible was by Henry $(1964 a, b)$. Using a set of equations similar to (2) - (5) (simplified to steady-state salt concentration and constant dispersion coefficient), he obtained an approximate analytical solution using a Fourier-Galerkin double series expansion approach. Due to computational resource limitations, Henry had to use unrealistic values for the significant parameters of the problem, yet he was able to achieve qualitative agreement with field observations. One of the important assumptions 
(and limitations) of Henry's solution is that it is valid only for relatively wide transition zones. Henry's approximate analytic solution is the only analytic solution to the density-coupled flow and transport formulation to the salt water intrusion problem. As a result, it is one of the few ways available to validate numerical solutions to the governing equations. In fact, the governing equations, boundary conditions and solution from Henry's work have come to be generally referred to in the literature as "Henry's problem" and "Henry's solution."

Pinder and Cooper (1970) provided the first numerical solution to Henry's problem, extending the solution to transient salt concentrations. They solved the flow equation using an alternating-direction, implicit finite-difference scheme, and the transport equation was solved with the method of characteristics. Lee and Cheng (1974) formulated the problem in terms of finite elements, with further refinements by Segol and Pinder (1976), Frind (1982) and Voss (1984), among others. The common approach to validation of these numerical solutions was to show that the numerical code could reproduce the analytic solution to Henry's problem, and in the later studies, to show that new numerical formulation could reproduce results from previous numerical computer codes. In general, the numerical solutions concentrated on problems with broad transition zones. The reasons for this were twofold: (1) Henry's solution is valid for broad transition zones; and (2) relatively large dispersion coefficients had to be used to minimize numerical dispersion and oscillation problems inherent in the numerical algorithms. The first study to consider the problem of a relatively narrow transition zone using a numerical solution to the density-coupled flow and transport equation set (as opposed to treating the problem as an immiscible two-phase flow problem) was by Voss and Souza (1987). In this paper, Voss and Souza suggest three criteria for the successful validation of a numerical solution to the density-coupled problem: (1) the code must have functionally consistent velocity calculations; (2) the code must be validated by a series of tests (successful simulation of Henry's solution is not enough); and (3) fine spatial discretization is necessary to allow accurate representation of a narrow transition zone.

The reason that Henry's problem is insufficient to validate a code is that the parameters in Henry's solution allow for only very weak coupling between the flow and the salt transport. As a result, it is possible that buoyancy-driven forces will be inadequately modeled. Voss and Souza go on to say (p. 1855) that "no model to date has successfully matched the Henry solution. ... This may indicate some inaccuracy in Henry's results, possibly due to missing higher-order terms which were originally dropped for the sake of reducing computation time." Since Henry's solution has no buoyancy-driven flow, Voss and Souza propose that the "Elder problem" (Elder, 1967) be used to validate the buoyant convection component of a numerical model of salt water intrusion.

It is clear that physical modeling of the salt water intrusion problem is important in terms of verifying the physics in the governing equations, and in terms of validating numerical solutions to 
the governing equations. Hele-Shaw analog models are useful for verifying immiscible two-phase flow models of salt water intrusion, but do not take into account the effects of dispersion or diffusion across the salt water/fresh water interface. Sandbox models are the only physical models that are capable of modeling all the important physical processes because they are a true physical analog for the problem. There have been a few sandbox model studies of salt water intrusion. Lau (1967) developed a sandbox model to study water supply problems on the island of Oahu, Hawaii, which included salt water intrusion. Peterson et al. (1978) developed a sandbox model to study liquid waste injection into an aquifer intruded with salt water.

The only known study which has directly compared the results of a numerical model of salt water intrusion to sandbox model studies is that of Wheatcraft and Peterson (1979). Results of the sandbox model studies alone were reported in Peterson et al. (1978). Wheatcraft and Peterson were able only to compare the results of the numerical solution and the sandbox model on a qualitative basis because of the limitations of computational resources and the numerical dispersion and oscillation inherent in the numerical solution. One thing they noticed with regard to the sandbox model experiments was that the transition zone between fresh and salt water remained extremely narrow (less than one $\mathrm{cm}$ in a sandbox that was about $2 \mathrm{~m} \mathrm{x} 1 \mathrm{~m} \times 1 \mathrm{~m}$ ). Peterson et al. (1978) were focusing on the fate of liquid effluent injected into the salt water zone, rather than on the salt water intrusion problem alone. But the major conclusion from their sandbox experiments was that the effluent plume (of fresh water density) rose through the salt water and into the fresh water zone with almost no mixing between the effluent plume and the surrounding salt water. Predictions of salt flux across the narrow transition zone based on simple molecular diffusion alone would predict much more mixing than was seen in these experiments.

\section{GEOLOGY OF AMCHITKA ISLAND}

The geology of Amchitka Island is characterized by surficial tundra, underlain by irregular layers of peat. The surficial material (tundra and peat) thickness ranges from zero to nearly $10 \mathrm{~m}$. The bedrock beneath the surficial material is the Banjo Point formation, which is Oligocene or Miocene in age. The Banjo Point formation is composed primarily of volcanic breccia, with lesser amounts of detrital sediments. The formation strikes generally northeast and dips gently southeast. The Banjo Point formation is at least $1,200 \mathrm{~m}$ thick at the Long Shot site. It is underlain by the Chitka Point formation, which may be in excess of $2,000 \mathrm{~m}$ thick. Additional information regarding the geology of Amchitka Island can be found in Gard and Hale (1964) and Fenske (1972). 


\section{AMCHITKA ISLAND CONCEPTUAL MODEL, GEOMETRY AND BOUNDARY CONDITIONS}

From Figure 1, it can be seen that Amchitka Island is a long, narrow island. As a result, it is very reasonable to model the groundwater system in the two-dimensional vertical plane perpendicular to the long axis of the island. The cross section is taken at a point which approximately intersects the Cannikin ground zero, about halfway along the long axis. Figure 4 shows a simplified sketch of this cross section (see A-A' in Figure 1). Because recharge is expected to be distributed evenly across the island, a water divide will bisect the island along its long axis, providing a plane of symmetry with a no-flow boundary, as shown in Figure 4.

\section{Geometry}

The right-hand boundary and the bottom boundary need to be far enough away from the fresh water lens so that they will not affect the solution. A series of initial simulations was performed to determine the appropriate size of the modeled domain, as compared to the actual island and fresh water lens. These simulations led to the conclusion that the modeled domain should be three times the island half-width in the horizontal direction, and at least twice the thickness of the fresh water lens in the vertical direction. Since the island half-width is approximately $2,000 \mathrm{~m}$ at the A-A' cross section, the horizontal width of the model was set to $6,000 \mathrm{~m}$. The fresh water lens (as measured by distance to the mid-point of the transition zone) is about $1200 \mathrm{~m}$ thick. This would lead to a vertical thickness for the model of $1,500 \mathrm{~m}$. However, to allow for sensitivity analysis, it was desirable to model a lens somewhat thicker than field data would indicate. The vertical model thickness was therefore selected to be $4,000 \mathrm{~m}$. Figure 5 summarizes the geometry and boundary conditions used in the simulations reported on herein. The system was modeled as a perfect rectangle (unlike Figure 4) because the ocean depth is negligible compared to the model thickness and it would not affect simulation results anyway.

\section{CHOICE OF MODEL PARAMETER VALUES}

The important model parameters for the Amchitka simulations were:

- recharge

- horizontal hydraulic conductivity

- vertical hydraulic conductivity

- longitudinal dispersivity

- transverse dispersivity. 


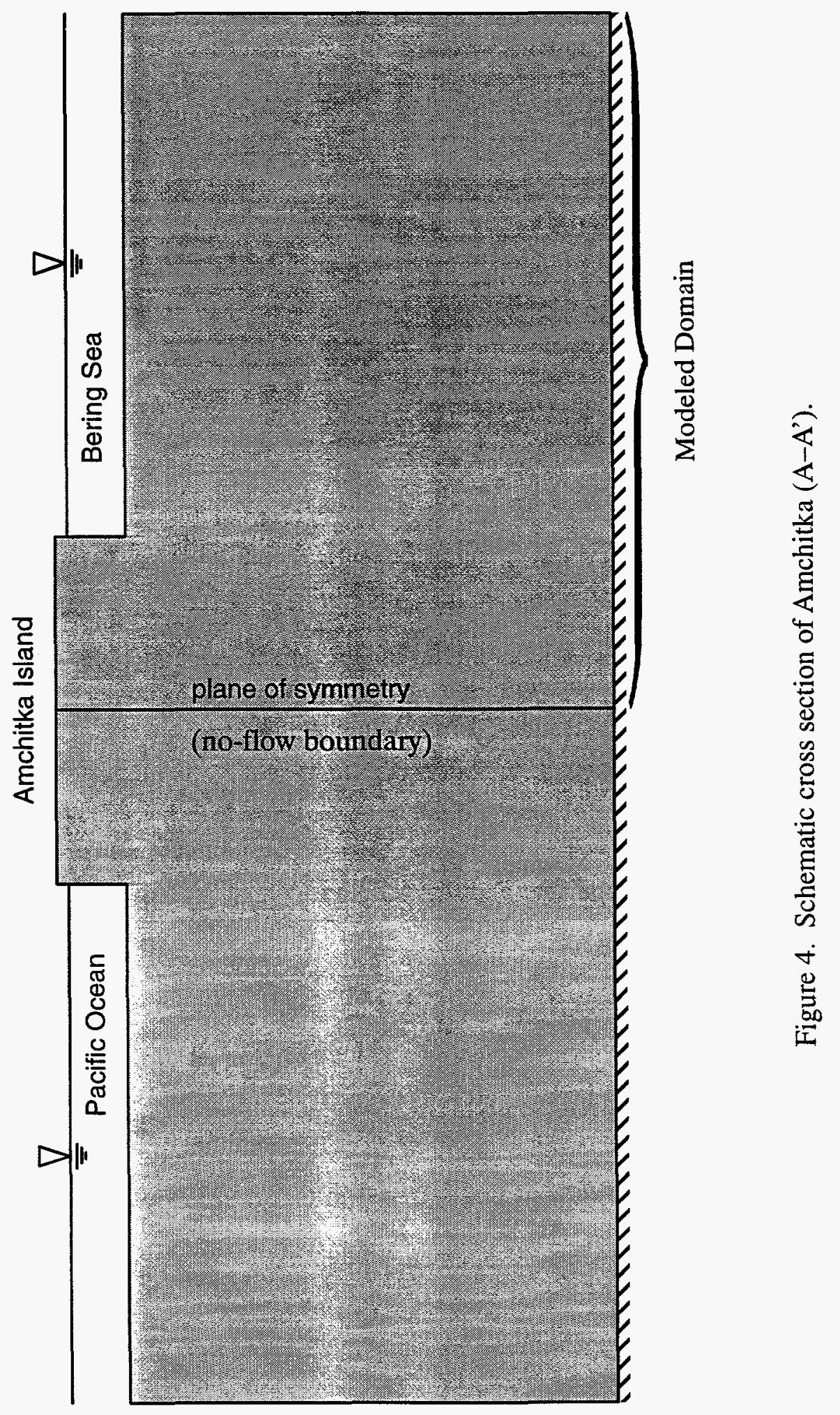




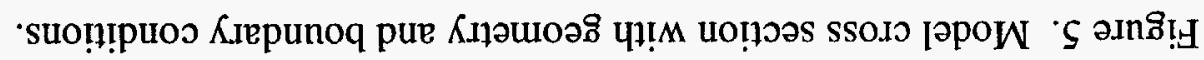

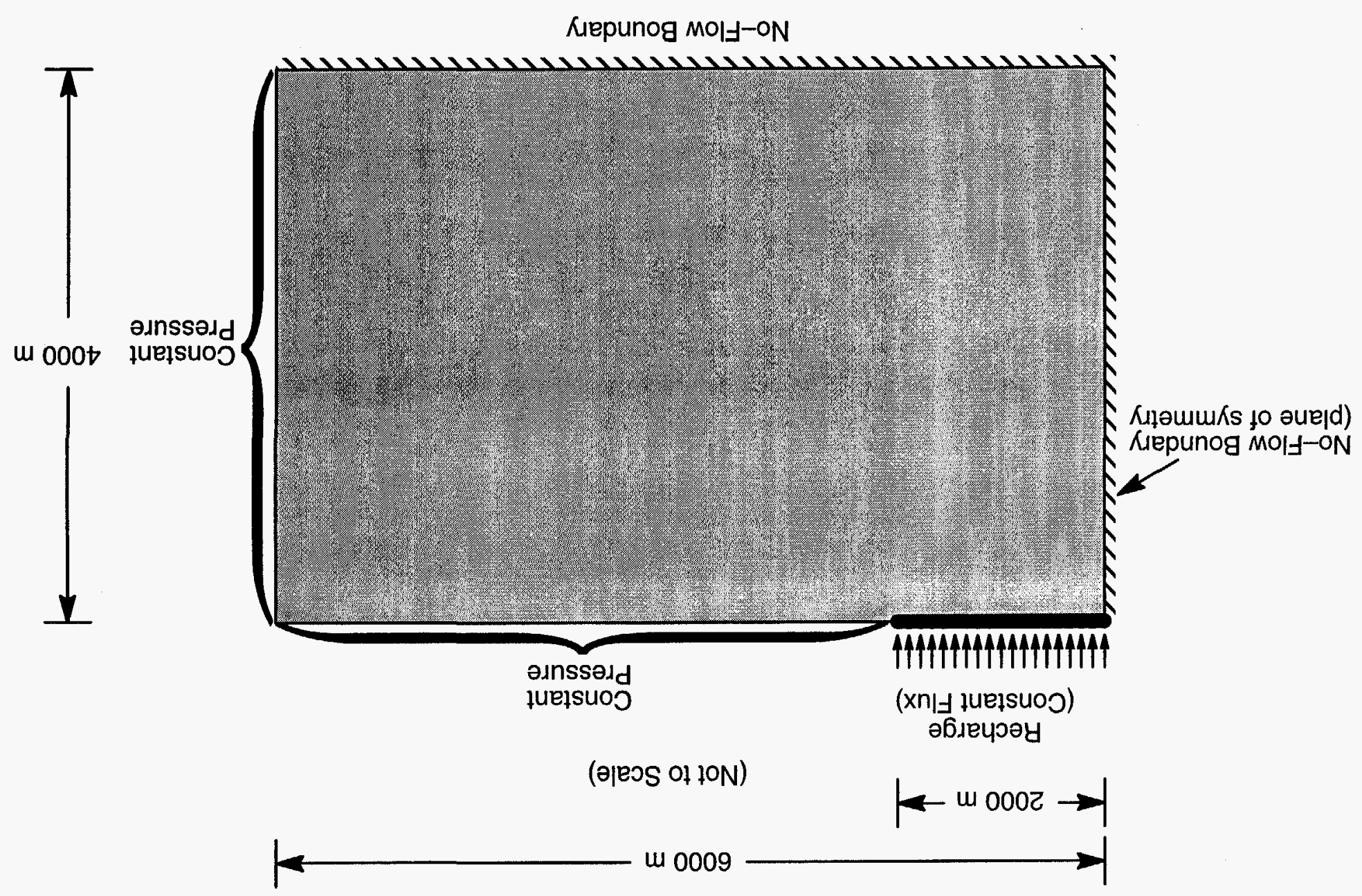




\section{Recharge}

Precipitation on Amchitka Island has been reported by Gard and Hale (1964) to be approximately $90 \mathrm{~cm} /$ year. Recharge is estimated to be from 4 to $12 \%$ of the total precipitation (Gard and Hale, 1964), or 4 to $11 \mathrm{~cm} /$ year. After some initial simulations, a value of $10 \mathrm{~cm} /$ year was chosen and used for the simulations reported on herein. This choice is discussed further in the section below entitled "Combining System Parameters."

\section{Hydraulic Conductivity}

Gard and Hale (1964) report values of hydraulic conductivity in the range of $0.1-0.3 \mathrm{~m} / \mathrm{d}$. In 1968, hole UAe-6H (see Figure 1 for location) was packer tested (Ballance, 1968) in 15 zones, ranging from $85 \mathrm{~m}$ to approximately $2,100 \mathrm{~m}$ deep; however, no reliable values of hydraulic conductivity were obtained. In 1972, hole UA-1-HTH-1 (see Figure 1 for location) was hydraulically tested (Ballance and Dinwiddie, 1972). Hydraulic conductivities were reported for three zones: $128-180 \mathrm{~m}: 6.5 \times 10^{-5} \mathrm{~m} / \mathrm{d} ; 183-235 \mathrm{~m}: 1.1 \times 10^{-1} \mathrm{~m} / \mathrm{d} ; 227-279 \mathrm{~m}: 8.2 \times 10^{-2} \mathrm{~m} / \mathrm{d}$. The values in the middle zone were similar to the ranges reported by Gard and Hale.

It is clear that the uncertainty in hydraulic conductivity is rather large for Amchitka Island, and this parameter was used as a sensitivity variable in the simulation series to be reported on.

It doesn't appear that any of the hydraulic tests were conducted in such a way as to allow the vertical hydraulic conductivity to be evaluated. Thus, nothing is known a priori regarding anisotropy ratios. As a result, the aquifer was assumed to be isotropic.

Because of the uncertainty surrounding values of hydraulic conductivity, and because of the limited scope of this project and report, no attempt was made to model individual geologic layers with different hydraulic conductivities in any of the simulations. However, it should be emphasized that considerable information exists regarding the subsurface geology of Amchitka and it would be possible to incorporate much of this information (at least on a relative basis) in a more sophisticated model. Such a model would require much more work than was possible under the scope of this project.

\section{Dispersivity}

There are no field-measured values for dispersivity, so the choices of these values are somewhat arbitrary, although there are important restrictions on their choice based on numerical considerations which will be discussed in the next section. In contaminant migration problems (especially those with an evolving plume), it is well known that dispersivity is scale dependent. Sea water intrusion problems are inherently different since there is no evolving plume that experiences larger and larger scales. Hence, there is no reason to suspect that dispersivity is scale dependent, as it 
is in contaminant migration problems. A common practice in sea water intrusion problems is to set the longitudinal dispersivity to a value that is approximately equal to grid spacing. This practice arises due to the numerical considerations of solving the governing equations. For the first set of simulations reported on here, a value of $200 \mathrm{~m}$ was chosen for the longitudinal dispersivity. The rationale for this choice is discussed in the section on numerical considerations. It is common in such cases to somewhat arbitrarily set the transverse dispersivity to be one-tenth the value of the longitudinal dispersivity, which was done in this study.

\section{Combining System Parameters}

Assuming that the system is isotropic, and that the dispersivity and system geometry (domain length and width) remain unchanged, the ratio of the recharge to the hydraulic conductivity completely determines system behavior (Henry, 1964a). Hence, a solution that matches field data in terms of fresh water lens thickness will have a unique ratio of recharge to hydraulic conductivity, yet one must know one of those two parameters to specify the correct value of the other one. As a result, the first series of simulations is a set of solutions for different recharge/hydraulic conductivity ratios. The details are provided in the section entitled "First Set of Simulations." The dimensionless recharge/hydraulic conductivity ratio is defined as:

$$
N_{r k}=\frac{R}{K}
$$

where $R=$ recharge and $K=$ hydraulic conductivity. Note that $R$ and $K$ need to be in consistent units so that $N_{r k}$ will be dimensionless. Ranges of values for $N_{r k}$ are discussed in the section entitled "First Set of Simulations."

As discussed above, because of the complete lack of field data regarding dispersivities, the transverse dispersivity was set to one-tenth the value of the longitudinal dispersivity for all simulations. Setting $a_{T}=1 / 10 a_{L}$ is a rule of thumb that is used in transport simulations when there is no specific information regarding transverse dispersivity values.

\section{CHOICE OF NUMERICAL CODE AND COMPUTERS}

There are a number of codes available that solve the governing equations for density-coupled flow and transport. The two most obvious choices are SUTRA (Voss, 1984) and MOCDENS (Sanford and Konikow, 1985). Both codes have been successfully compiled on the Silicon Graphics Inc. (SGI) computers in the author's computer labs. The computers available for this modeling project included an SGI Crimson VGX, two SGI Indigos and an SGI Indigo 2 Extreme. The Indigo 2 runs on a MIPS R4400 CPU, while the other three machines run on a MIPS R4000 CPU. SUTRA was chosen for these simulations primarily because we have added routines to our version of SUTRA on the SGI machines that automatically write output to Wavefront Technology's Data 
Visualizer $^{\odot}$, which is a state-of-the-art, two- and three-dimensional, scientific visualization program. The model output figures in this report were all produced with Data Visualizer ${ }^{\odot}$. Both codes have numerical restrictions in terms of their use for solving the advective-dispersion equation. In the next section, numerical considerations are discussed.

\section{NUMERICAL CONSIDERATIONS}

SUTRA is a finite element code and is therefore subject to certain numerical restrictions and limitations related to grid size, velocity and dispersivity. There are two important dimensionless numbers which must be taken into consideration: the grid Peclet number*, and the Courant number. The Peclet number is defined as (Voss, 1984):

$$
P_{e}=\frac{\Delta l}{a_{L}}
$$

where $\Delta l$ is the length of a model grid block and $a_{L}$ is the longitudinal dispersivity. To prevent numerical oscillation, $P_{e} \leq 2$ is required. This means that $a_{L} \geq \Delta l / 2$. Even though the dispersivity is not known for Amchitka, a reasonable value is $a_{L}=10 \mathrm{~m}$. Since the model dimensions are $6,000 \mathrm{~m} \mathrm{x}$ $4,000 \mathrm{~m}$, this means that we would need $600 \times 400$ grid blocks, for a total of 240,000 grid blocks and about 241,000 nodes. This size of a model would be prohibitive in terms of time, even on very fast scientific workstations such as the SGI machines that we have available in our labs. For instance, a 90 x 60 simulation takes about three hours on the SGI Indigo 2. Because of limitations of time on this project, the first set of simulations was conducted with $30 \times 20$ grid blocks, for a total of 600 grid blocks. To satisfy the $P_{e}$ number criteria (with a safety margin of a factor of two), the dispersivity was set equal to the length of a grid block. Hence, $a_{L}=200 \mathrm{~m}$ for the first set of simulations.

The Courant number is defined as (Voss, 1984):

$$
C r=\frac{V \Delta t}{\Delta l}
$$

where $V=$ average pore velocity, $\Delta l=$ length of grid block, and $\Delta t=$ time step length. The Courant number criterion is: $C r \leq 1$, implying that $\Delta t \leq \Delta l /$. Because there is a very large variation in velocities in a sea water intrusion problem, both in space and time, it is difficult to predict ahead of time whether a particular simulation will satisfy the Courant number criterion. In practice, it is best to take the largest time step possible that does not cause oscillation and/or instability in the solution.

It should also be noted that SUTRA input calls for intrinsic permeability, instead of hydraulic conductivity. However, since most hydrogeologists are more familiar with hydraulic conductivity,

\footnotetext{
${ }^{*}$ Hereafter referred to simply as the Peclet number.
} 
all values of intrinsic permeability used in the simulations are converted to hydraulic conductivity, using the following relationship:

$$
K=k \frac{\rho g}{\mu}
$$

where

$$
\begin{aligned}
\rho & =1000 \mathrm{~kg} / \mathrm{m}^{3} \\
\mu & =0.001 \mathrm{~kg} /(\mathrm{m}-\mathrm{s}) \\
g & =9.80 \mathrm{~m} / \mathrm{s}^{2}
\end{aligned}
$$

\section{FIRST SET OF SIMULATIONS}

The first set of simulations was performed to find the best value for $N_{r k}$, the dimensionless ratio of recharge to hydraulic conductivity. The simulations were carried out by starting with a relatively large ratio of $N_{r k}$, which yielded a fresh water lens considerably thicker than indicated from field data, and then run successive simulations in which $N_{r k}$ was systematically reduced until the fresh water lens was considerably thinner than indicated by field data.

Even though $N_{r k}$ was the unique parameter which varied in these simulations, there is considerably less uncertainty in the recharge value, as compared to the hydraulic conductivity value. Gard and Hale (1964) report 4 to $11 \mathrm{~cm} / \mathrm{yr}$ as the most likely range of recharge values, less than an order of magnitude of uncertainty. However, hydraulic conductivity values range from $6.5 \times 10^{-5}$ to 1 $x 10^{-1} \mathrm{~m} / \mathrm{d}$, nearly five orders of magnitude. Because of the relative uncertainty in estimation and spatial variation of hydraulic conductivity values, as compared to recharge, the first set of simulations is discussed in terms of varying the hydraulic conductivity, with the assumption of a recharge value of $10 \mathrm{~cm} / \mathrm{yr}$. Table 1 shows the hydraulic conductivity values, and the associated $N_{r k}$ values for the first set of simulations. Values of intrinsic permeability are included in Table 1 for the sake of completeness, since these are the actual values that SUTRA uses as input.

During preliminary simulations, it was found that $N_{r k}$ (or hydraulic conductivity) had to be incremented (or decremented) geometrically to produce an arithmetic change in the thickness of the fresh water lens. Hence, for the first set of simulations, the smallest value of hydraulic conductivity that was used, which we will call $\mathrm{K}_{1}$, was $1.0 \times 10^{-2} \mathrm{~m} / \mathrm{d}$. Hydraulic conductivity values were then incremented by the formula:

$$
K_{i+1}=\lambda K_{i}
$$

where

$$
\lambda=e^{\frac{\ln 10}{n}}, \quad(n=5)
$$


TABLE 1. PARAMETER VALUES FOR FIRST SET OF SIMULATIONS ( $N_{r k}$ values obtained by assuming $10 \mathrm{~cm} / \mathrm{yr}$ recharge).

\begin{tabular}{ccc}
\hline $\begin{array}{c}\text { Hydraulic } \\
\text { Conductivity (m/d) }\end{array}$ & $\begin{array}{c}\text { Intrinsic } \\
\text { Permeability (m2) }\end{array}$ & $N_{r k}$ \\
\hline $1.00 \times 10^{-2}$ & $1.18 \times 10^{-14}$ & $2.74 \times 10^{-2}$ \\
$1.58 \times 10^{-2}$ & $1.87 \times 10^{-14}$ & $1.73 \times 10^{-2}$ \\
$2.51 \times 10^{-2}$ & $2.97 \times 10^{-14}$ & $1.09 \times 10^{-2}$ \\
$3.98 \times 10^{-2}$ & $4.70 \times 10^{-14}$ & $6.88 \times 10^{-3}$ \\
$6.31 \times 10^{-2}$ & $7.45 \times 10^{-14}$ & $4.34 \times 10^{-3}$ \\
$1.00 \times 10^{-1}$ & $1.18 \times 10^{-13}$ & $2.74 \times 10^{-3}$ \\
$1.58 \times 10^{-1}$ & $1.87 \times 10^{-13}$ & $1.73 \times 10^{-3}$ \\
$2.51 \times 10^{-1}$ & $2.97 \times 10^{-13}$ & $1.09 \times 10^{-3}$ \\
$3.98 \times 10^{-1}$ & $4.70 \times 10^{-13}$ & $6.88 \times 10^{-4}$ \\
$6.31 \times 10^{-1}$ & $7.45 \times 10^{-13}$ & $4.34 \times 10^{-4}$ \\
$1.00 \times 10^{0}$ & $1.18 \times 10^{-12}$ & $2.74 \times 10^{-4}$ \\
\hline
\end{tabular}

The choice of $n=5$ yields five values of hydraulic conductivity per log cycle (evenly spaced, if plotted on log paper).

\section{Simulation Results}

The steady-state salinity distributions for the 11 simulations are presented in Appendix 1. The left-hand side of the problem domain represents the salinity distribution (and hence, the fresh water thickness) at the center of the island. Gard and Hale (1964) indicate that the fresh water thickness (as defined by the distance from the water table to the center of the transition zone) is about $1200 \mathrm{~m}$. The simulation which is closest to this is the one with a hydraulic conductivity of $3.98 \times 10^{-2} \mathrm{~m} / \mathrm{d}$. Hence, it can be concluded that a fresh water lens thickness (at the island center) of $1200 \mathrm{~m}$ can be obtained with a recharge of $0.1 \mathrm{~m} / \mathrm{yr}$ and a hydraulic conductivity of approximately $0.04 \mathrm{~m} / \mathrm{d}$. It is important to emphasize that $N_{r k}$ for these values of recharge and hydraulic conductivity is: $N_{r k}=6.88 \times 10^{-3}$. Hence, this solution is correct (i.e., closest to known field data regarding fresh water lens thickness) for any combination of values of recharge and hydraulic conductivity which yield $N_{r k}=6.88 \times 10^{-3}$. Conversely, if the fresh water lens thickness has changed, or future better field data indicate that the thickness is significantly different than the $1200 \mathrm{~m}$ indicated by Gard and Hale (1964), this first set of simulations provides an entire range of solutions from which to choose. One can select the simulation which most closely represents field data on fresh water lens thickness and distribution, then one immediately knows the associated value of $N_{r k}$ that will produce the desired fresh water 
lens. Because $N_{r k}$ is the parameter which governs the nature of the solution, it points out the need to better define the values of recharge and hydraulic conductivity in future studies on Amchitka.

\section{SECOND SET OF SIMULATIONS}

Because the first set of simulations is done at a relatively coarse grid ( $30 \times 20$ elements), they are meant to be used primarily for the purpose of determining the value of $N_{r k}$ which best fits the known fresh water lens. It is best to conduct further analysis based on higher resolution simulations.

The second set of simulations was conducted at a grid of $90 \times 60$ elements. These simulations use the same system geometry (total horizontal length $=6,000 \mathrm{~m}$, total vertical depth $=4,000 \mathrm{~m}$ ). The island half-width is again $2,000 \mathrm{~m}$; so Figure 5 also applies to the second set of simulations.

Now that we have a value for $N_{r k}$ that fits the field data with respect to the fresh water lens thickness, there is no need to repeat the incremental series of 11 simulations that we did with the first set. We will assume that $N_{r k}=6.88 \times 10^{-3}$ is the correct value for this parameter. The only parameters that are still considered relatively uncertain are the longitudinal and transverse dispersivities. Due to the grid Peclet number criteria, the smallest value of longitudinal dispersivity that we can use is $a_{L}=$ $33.3 \mathrm{~m}$. The second set of simulations consists of three simulations, with $a_{L}=33.3 \mathrm{~m}, a_{L}=66.7 \mathrm{~m}$ and

$a_{L}=133 \mathrm{~m}$. The transverse dispersivity was set to one-tenth the value of the longitudinal dispersivity, as in the first set of simulations. The ratio of longitudinal-to-transverse dispersivity was not varied for any of the simulations conducted in this study. Therefore, in the following discussions, the term "dispersivity" will be used for brevity, with the understanding that we are actually talking about the longitudinal dispersivity.

\section{Simulation Results}

Figures 6,7 and 8 show the steady-state salinity distributions for the three simulations with varying dispersivity values. As the dispersivity increases, the transition zone gets correspondingly wider. Although the correct value of dispersivity is not known, further analysis will focus on the simulations in which the dispersivities are $33.3 \mathrm{~m}$ and $66.7 \mathrm{~m}$ (Figures 6 and 7, respectively). As previously discussed, scale-dependent growth of dispersivity in sea water intrusion regimes is not expected to be a major factor; therefore, it is likely that the smaller dispersivity values will better represent the system.

Figures 9 and 10 show the vector velocity field superimposed on the salinity distribution in a close-up view centered on the fresh water lens portion of the simulation. In these two figures, every small white dot in the dark gray region represents an element in the model, and its associated velocity vector. The vectors are so small compared to the velocity magnitude in the zone where fresh water exits into the ocean that they appear as dots, rather than as lines. The first 30 vectors on the 


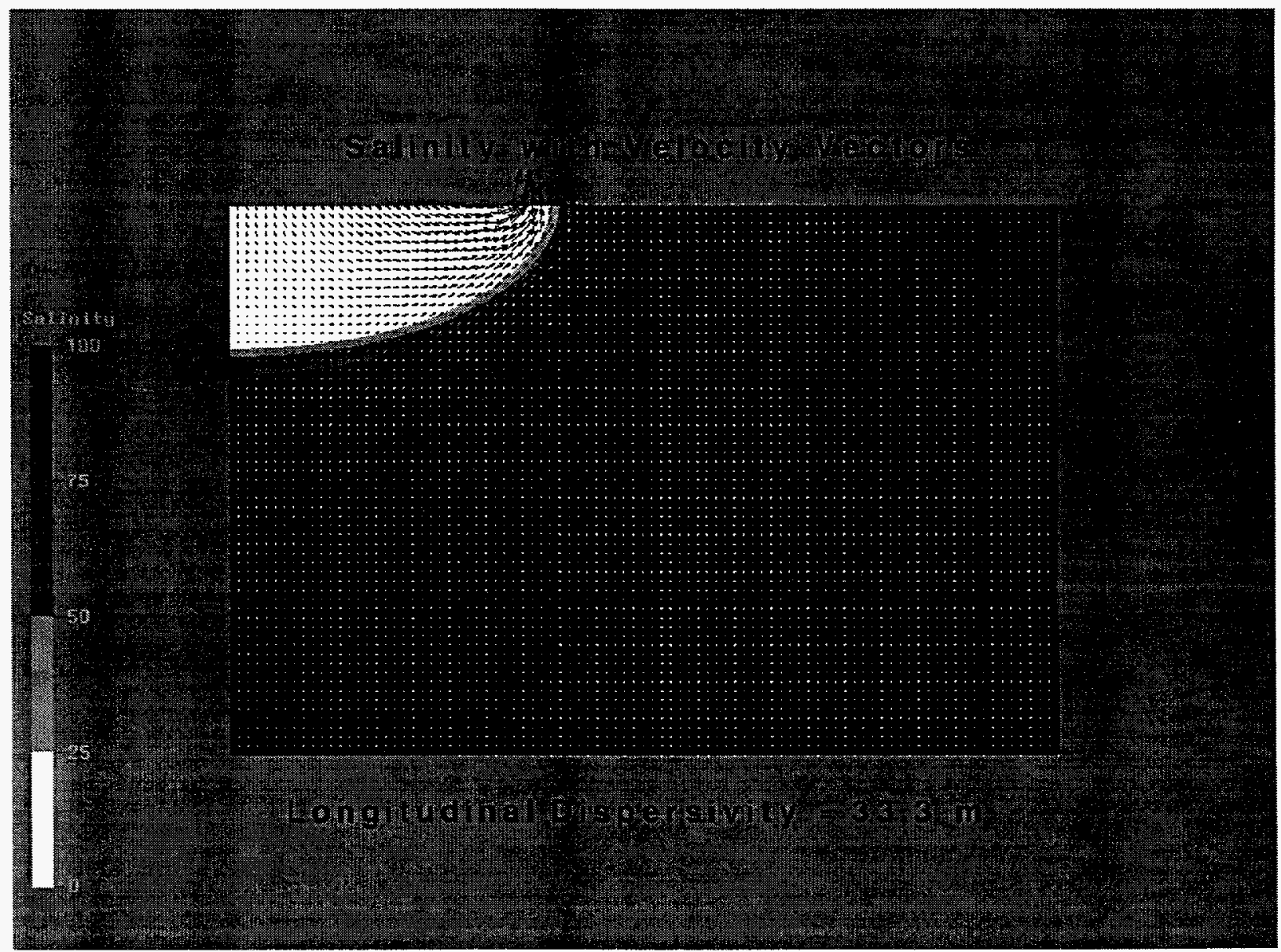

Figure 6. Steady-state salinity distribution: $\mathrm{a}_{\mathrm{L}}=33.3 \mathrm{~m}$. 


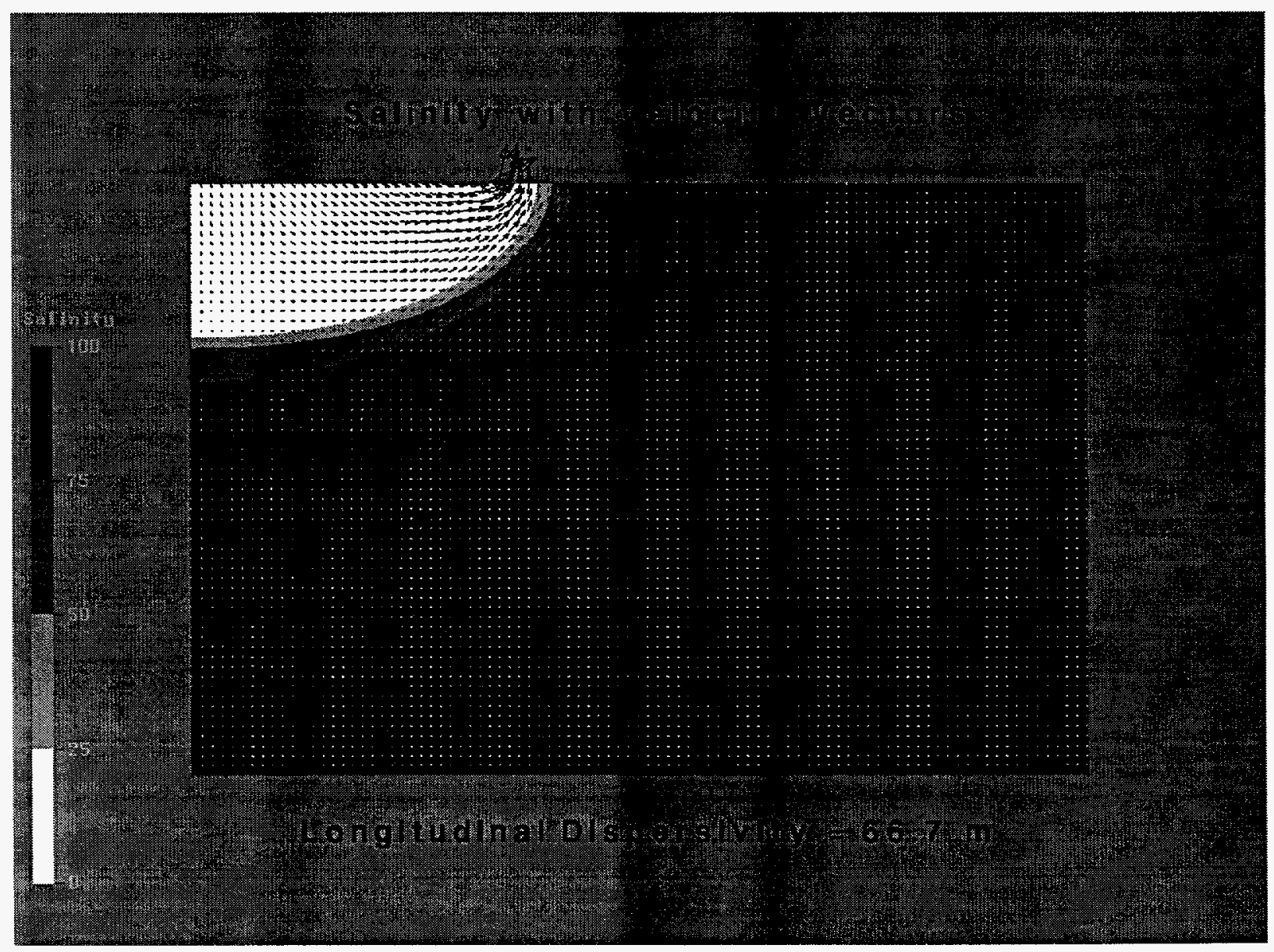

Figure 7. Steady-state salinity distribution: $\mathrm{a}_{\mathrm{L}}=66.7 \mathrm{~m}$. 


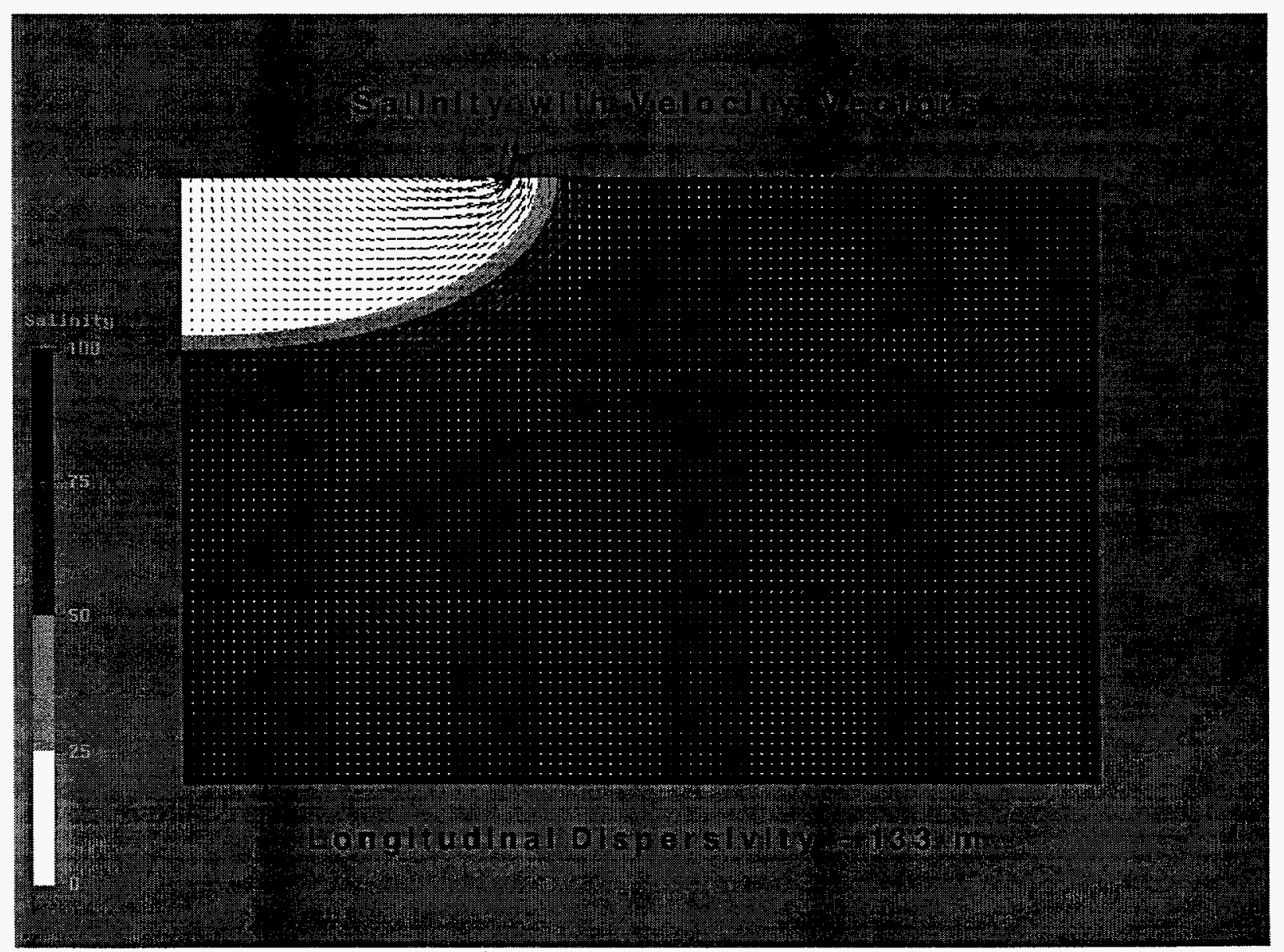

Figure 8. Steady-state salinity distribution: $\mathrm{a}_{\mathrm{L}}=133 \mathrm{~m}$. 


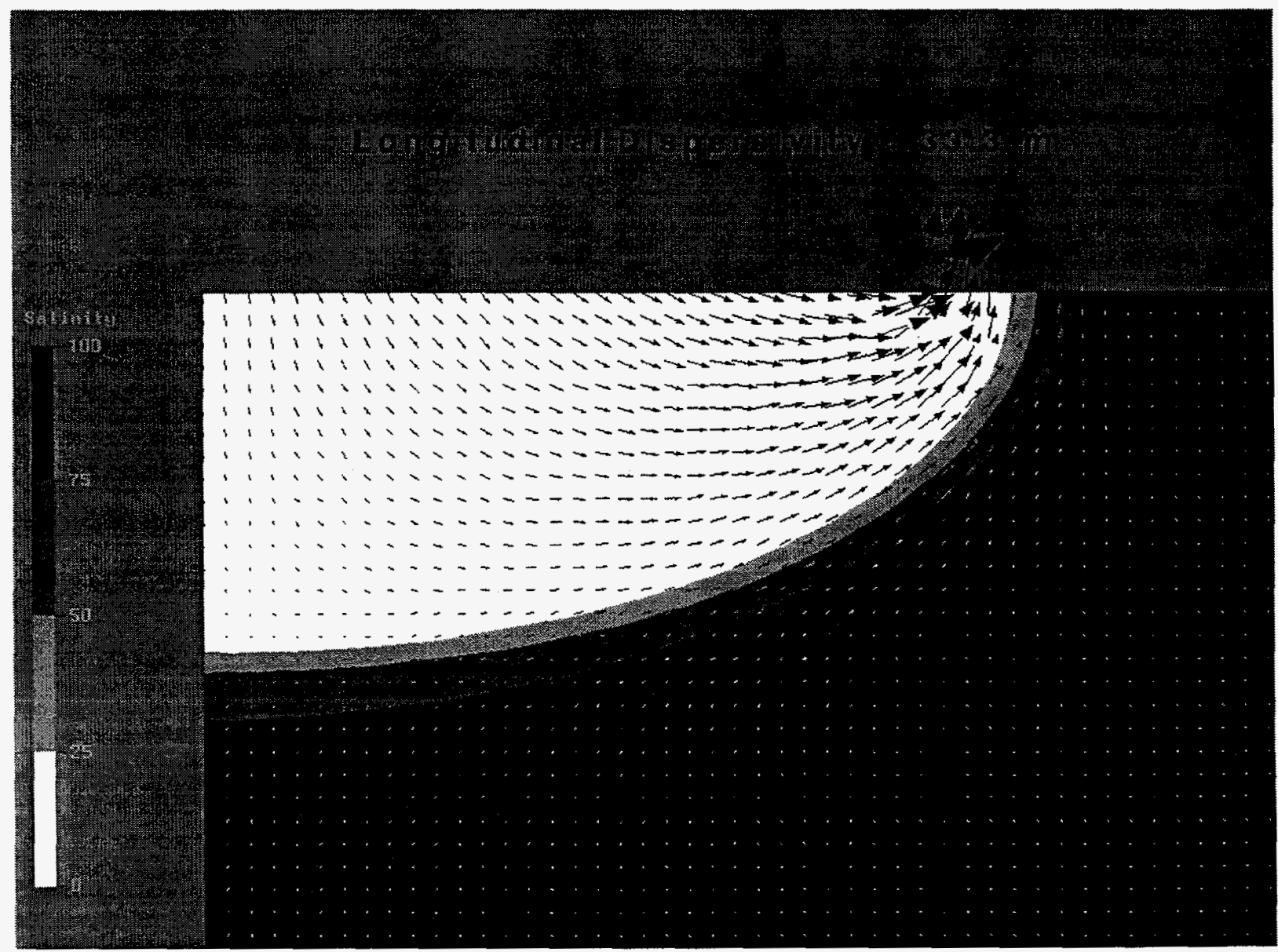

Figure 9. Steady-state salinity distributions with velocity vectors: $\mathrm{a}_{\mathrm{L}}=66.7 \mathrm{~m}$. 


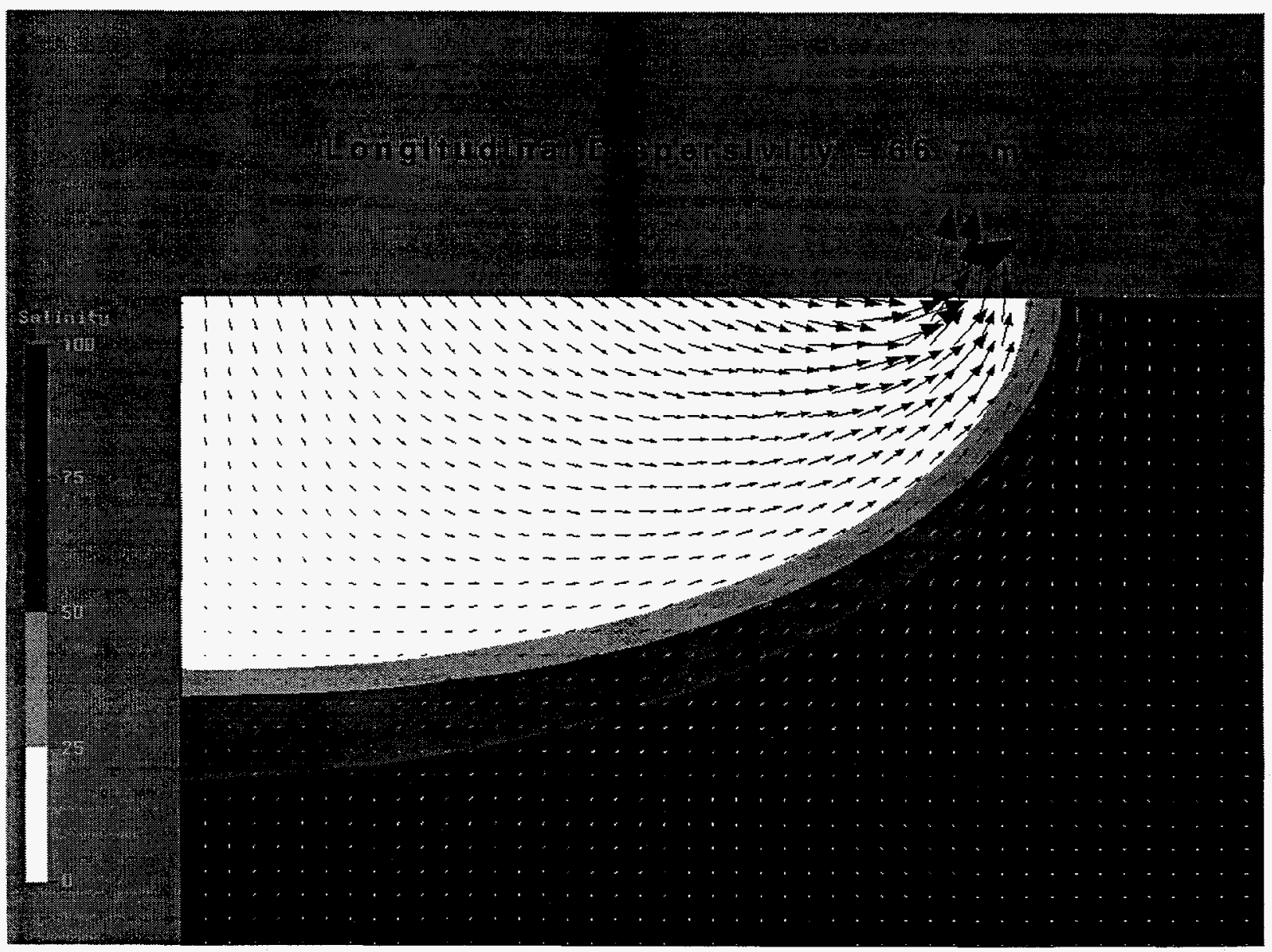

Figure 10. Steady-state salinity distributions with velocity vectors: $a_{L}=133 \mathrm{~m}$. 
topmostrow all have a downward component due to the recharge. The 31st-34th vectors (on the top row) all have strong positive vertical components, reflecting the rather large fluxes of fresh water that exit into the near-shore portion of the ocean. Once the fresh water exits into the ocean, it will be rapidly mixed with the ocean water. In theory, it is possible to detect near-shore fresh water fluxes by geophysical techniques such as infrared aerial photography, which can pick up temperature differences between the exiting fresh water and the ambient ocean water. It might also be possible to detect fresh water fluxes with seepage meters. These would be important considerations in planning future field efforts at the site.

Figure 11 shows the piezometric head contours. Heads in the center of the island are about 35 $\mathrm{m}$, which is just about what one would expect from the simple Ghyben-Herzberg relationship (Equation 1). Gard and Hale (1964), in their Figure 3, show fresh water heads of about $38 \mathrm{~m}$ near the center of the island, which is in good agreement with the simulated heads, especially considering the lack of good permeability data. Figure 11 clearly illustrates the areas where heads change rapidly, and the vast areas in the lower and ocean-side portions of the model where heads change very gradually and flow takes place extremely slowly.

Figure 12 shows a set of streaklines started at uniformly spaced points on a two-dimensional grid. It shows the overall circulation pattern for the system. Flux rates in the transition zone can be seen to be very high compared to other parts of the domain. As sea water in the transition zone is stripped away, exiting with the fresh water recharge near the island shore, the transition zone sea water is replaced with recirculation from sea water-saturated materials beneath the island and the ocean. Flow rates farther away from the island (to the right and towards the bottom) are very slow compared to flow rates in and around the fresh water lens.

This point is illustrated better in Figure 13, which shows sets of streaklines started at uniformly spaced points along the top and left-hand sides and along a bisection in the middle of the model domain. These streaklines were all started from their "starting lines" at the same time. Very little movement is seen along the bisecting line in the middle of the domain, and along the top right-hand portion. However, the streaklines that start from the island surface (top left-hand portion) have moved from their starting point to, in some cases, their exit point in the near-shore discharge area.

\section{TRAVEL TIMES (RESIDENCE TIMES) FOR THE MODELED SYSTEM}

Figure 14 illustrates the rapidly changing travel times (or residence times) for particles, depending on how far away from the ocean they start their journey. There are eight streaklines, spaced $100 \mathrm{~m}$ apart, starting $100 \mathrm{~m}$ from the island center, going $800 \mathrm{~m}$ towards the ocean. Each streakline represents 500 years of travel. The model grid structure has been superimposed for scale: each grid block is $66.7 \mathrm{~m}$ on a side. The particle that starts $100 \mathrm{~m}$ from the island center only travels a 


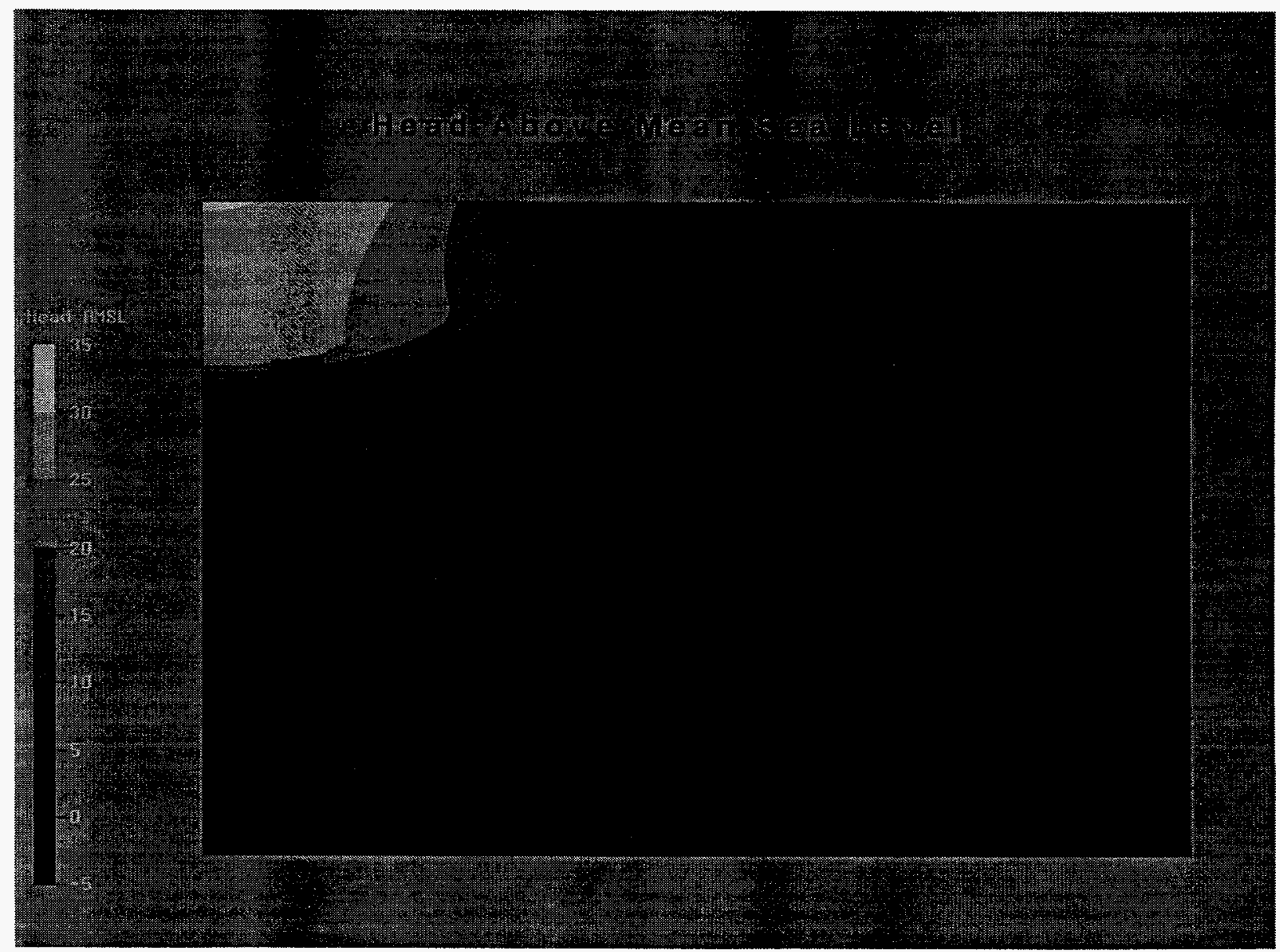

Figure 11. Steady-state head distributions for the best-fit set of parameters. 


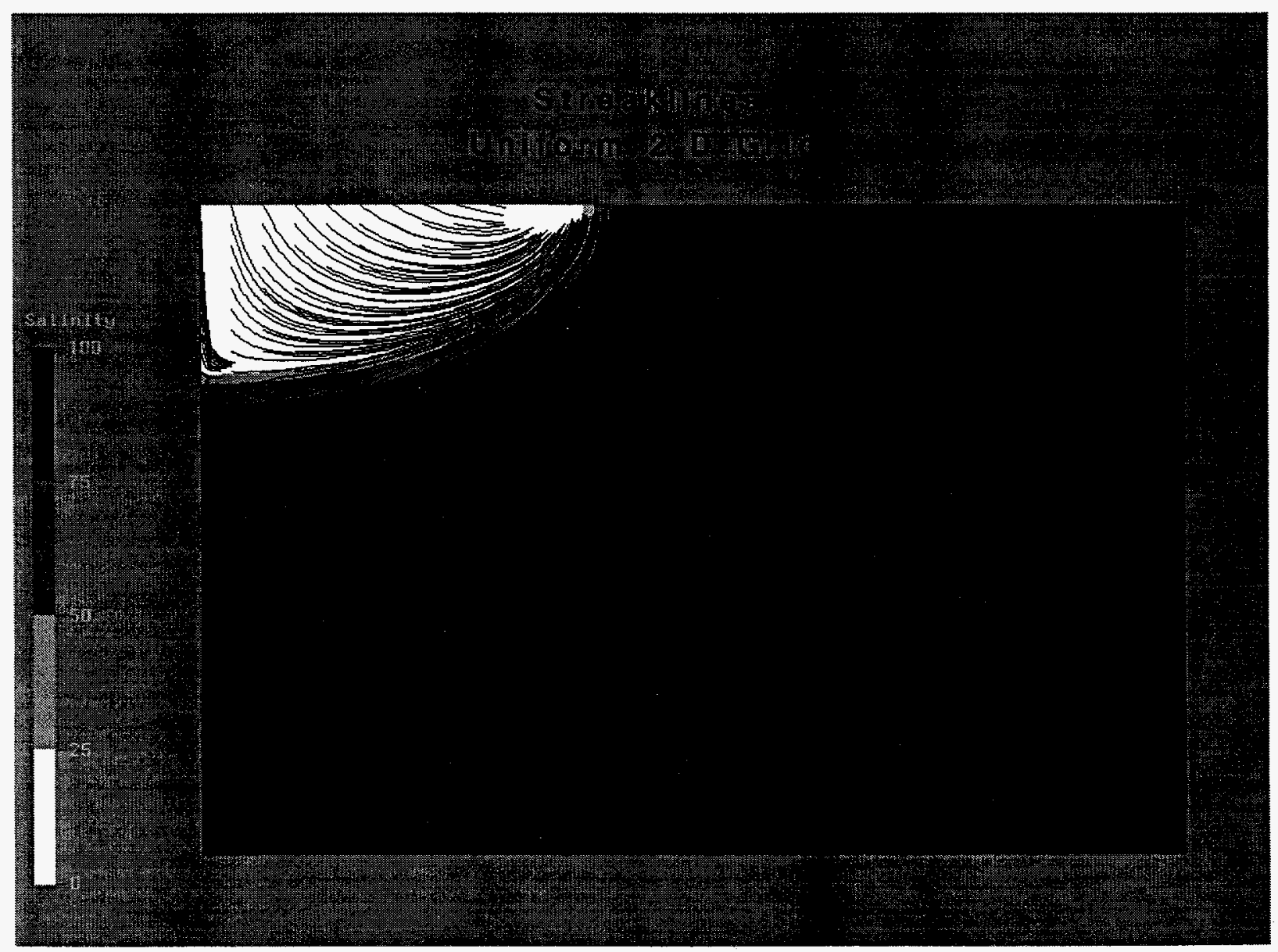

Figure 12. Uniformly distributed streaklines for the best-fit set of parameters. 


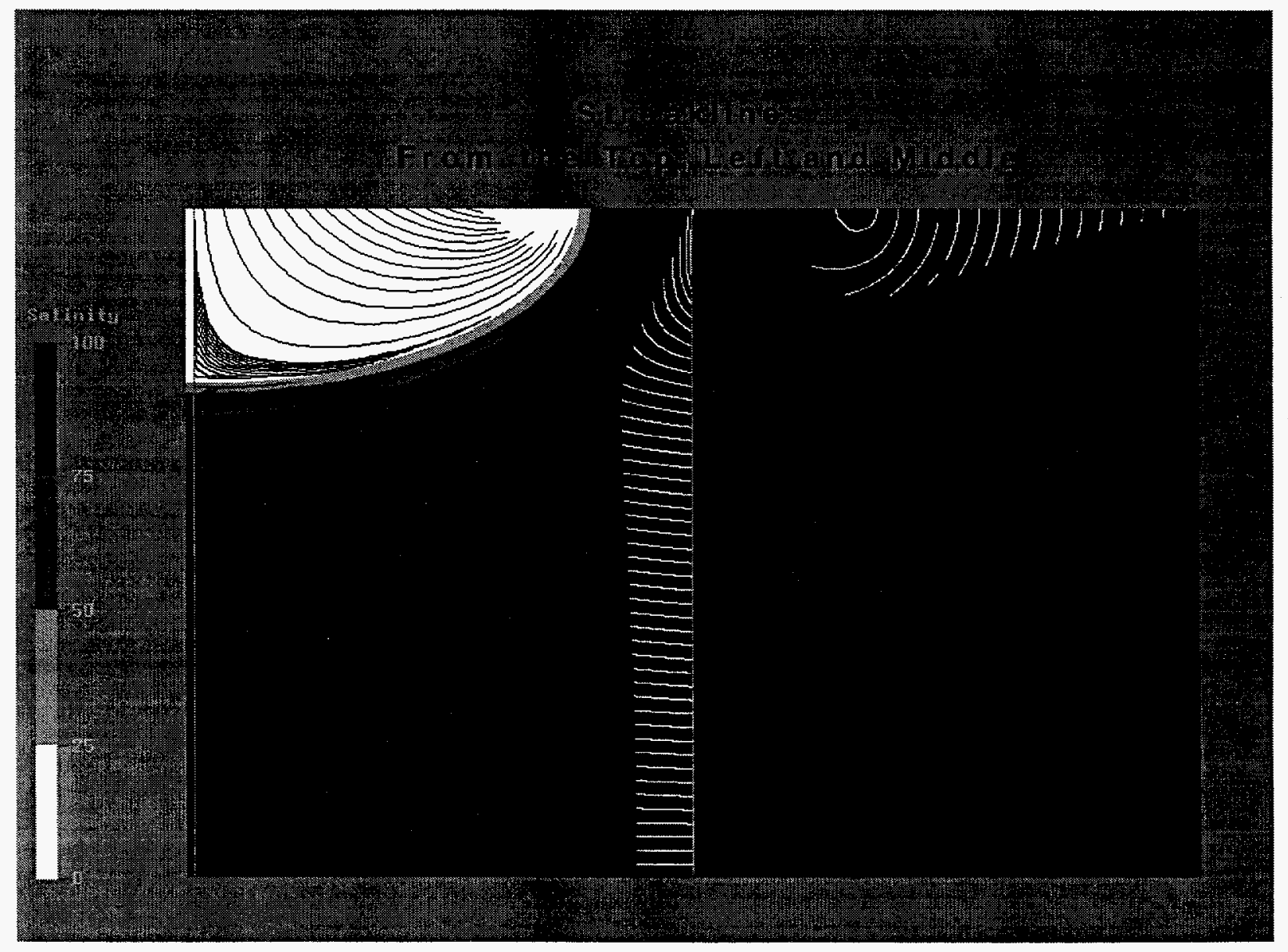

Figure 13. Streaklines placed on three sides to show relative velocities. 


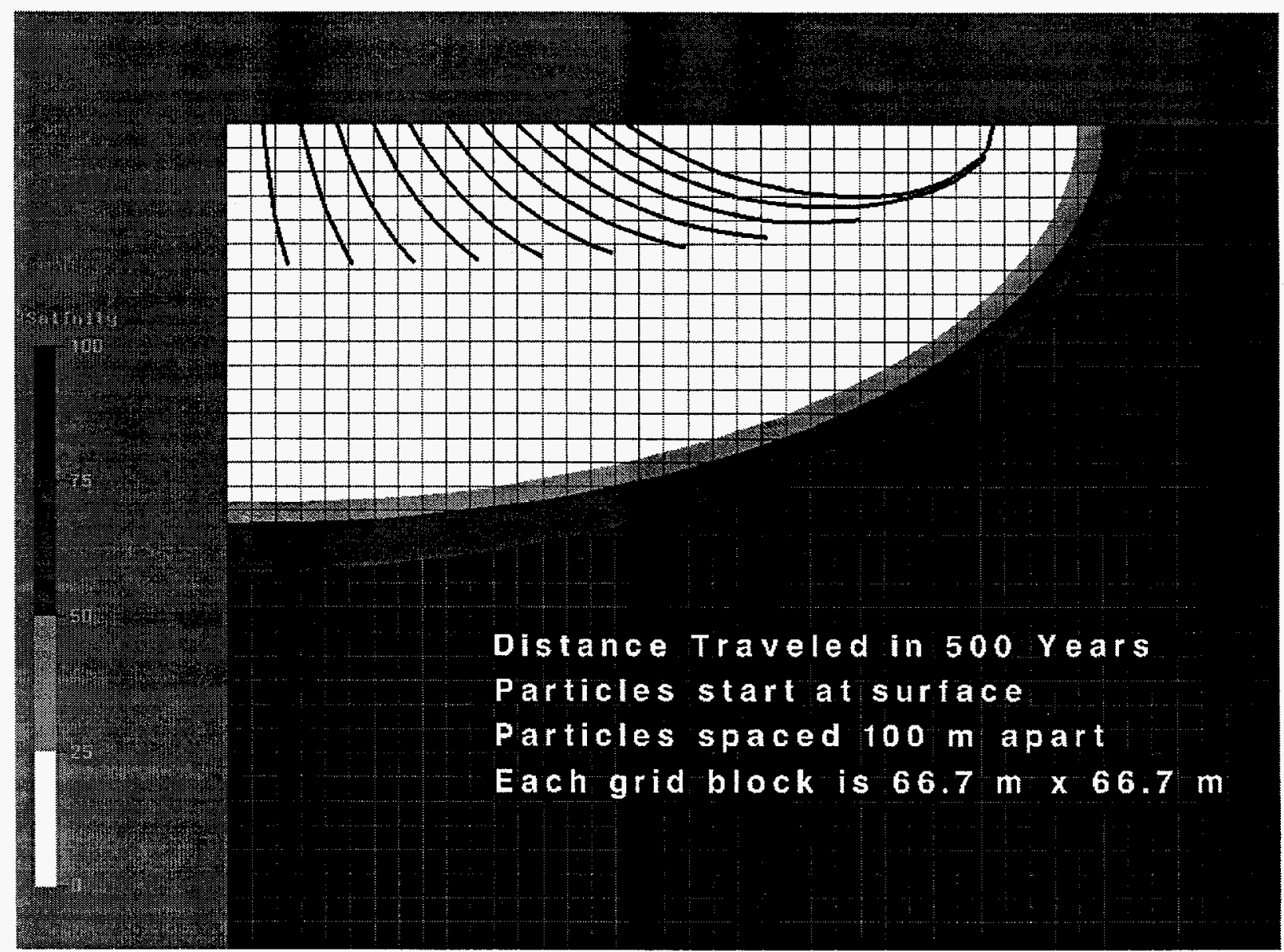

Figure 14. Streaklines for 500-year travel time for fresh water recharge source. 
few hundred meters in 500 years, but the particle that starts $800 \mathrm{~m}$ from the island center $(1200 \mathrm{~m}$ from the ocean) actually reaches the ocean in 500 years.

Figure 15 has two streaklines placed on it. The upper one is placed at the center of the working point for the Long Shot event (according to Figure 3, Gard and Hale, 1964). The streakline was set to be just long enough (and no more) to exit into the ocean. This streakline represents 800 years of travel time. Hence, this model predicts that water from the center of the working point of Long Shot will take 800 years to exit into the ocean.

One must be careful in making such predictions. This point is illustrated by the second streakline, placed below the Long Shot working point, in the center of the transition zone. This particle takes about 1770 years to reach the ocean. It is clear that the position of the transition zone relative to the Long Shot (or any of the other tests) working point is very important in determining travel times to the ocean.

The choice of dispersivity values also has an effect on travel time calculations. The smaller the dispersivity (both longitudinal and transverse), the longer the residence times of salt water moving through the lower portion of the aquifer and transition zone.

\section{CONCLUSIONS}

The groundwater system of Amchitka Island has been developed into the conceptual model shown in Figure 5. A single, dimensionless parameter, $N_{r k}$, the ratio of vertical recharge from precipitation to the hydraulic conductivity, governs the system behavior in terms of fresh water lens thickness and distribution. For a lens that is $1200 \mathrm{~m}$ thick at the center of the island, $N_{r k}=6.88 \times 10^{-3}$. For a recharge value of $10 \mathrm{~cm} / \mathrm{yr}$, the hydraulic conductivity would be about $0.04 \mathrm{~m} / \mathrm{d}$, which is in agreement with values reported by Gard and Hale (1964). Residence times for water in the fresh water system (from time of recharge until exiting the system at the ocean) range from less than 100 years to more than 2000 years. Water from the vicinity of the Long Shot working point would take about 900 years to exit the groundwater system to the ocean. Appendix A provides an entire set of solutions for different values of $N_{r k}$, which yield correspondingly different fresh water lens thicknesses and distributions. The dispersivity affects the width of the transition zone (and to a lesser extent, the fresh water lens thickness), but it is likely that additional simulations will need to be done with a variable mesh design to obtain a solution with a realistic dispersivity value. Additional refinements in the model would include multiple geologic layers with differing hydraulic conductivities. This information is available, to a limited extent, from original reports on island hydrogeology and hydraulic tests. 


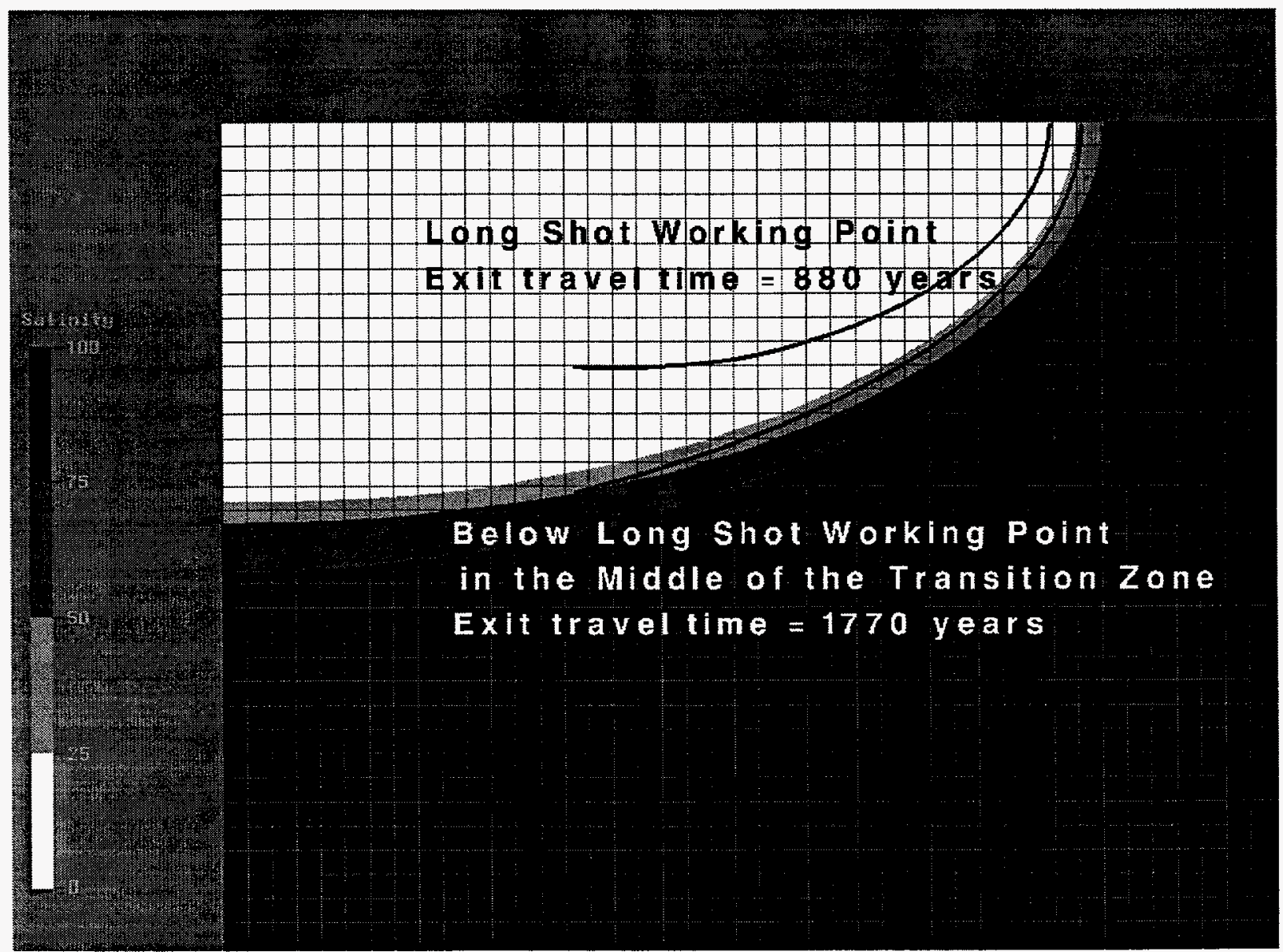

Figure 15. Streaklines for particles originating above and in the Long Shot working point. 


\section{MODEL LIMITATIONS}

The limitations of this model need to be well understood. The model assumes spatially and temporally constant recharge from the island surface. The system is modeled as isotropic and homogeneous, and it is most probably neither. Even with the higher-resolution second set of simulations, the true dispersivity is probably much smaller than was practical to model in the current work. This model neglects any tidal effects on the lens structure (which are at present unknown).

\section{FURTHER WORK}

This preliminary modeling exercise illustrates that there are some important issues that need to be resolved or investigated further both in terms of field work and further quantitative analysis.

\section{Field Work}

The model developed here can be used to guide further field work, in terms of the type of information that needs to be collected and where it needs to be collected. It would be helpful to have several wells on a transect (similar to A-A' in Figure 1) from the center of the island to near the ocean. Vertical salinity profiles from these wells would provide information to better calibrate the model in terms of the value of $N_{r k}$, and the value of dispersivity. To optimize resources, the transect could start at the island center and go towards the Bering Sea (or towards the Pacific Ocean). It would be best to locate a well reasonably close to Cannikin, but outside the influence of the test, to precisely locate the shot with regard to the freshwater lens and transition zone. In addition to the vertical salinity profiles, a number of hydraulic tests could be performed with these wells. Important information would include packer tests to obtain hydraulic conductivity values and areal distribution for specific geologic formations. In the wells near the ocean, data regarding vertical distribution in head would be extremely useful in verifying the model. It is clear from the model data, as would be expected with any sea water intrusion problem, that the area right around the coast is most important, because velocities and salinity distributions change rapidly in this area. Seepage meters installed on the near-shore ocean bottom would provide direct field evidence regarding fresh water flux rates. It would also be helpful to install monitoring recorders with pressure transducers in several wells, and in the ocean, so that an analysis of tidal effects on the groundwater system could be done.

\section{Modeling}

Some additional modeling efforts would be useful, even without additional data collected from the field, as observed above. A completely irregular element mesh could be designed, making use of the modeling results from this study, which would allow modeling of the system with smaller (and probably more realistic) values of dispersivity. Additional modeling efforts would then be warranted after more and better information becomes available from the field. Because Amchitka Island is very 
long and narrow, it seems unlikely that a fully three-dimensional model would ever be required to provide better understanding of the system than that obtained from a two-dimensional, vertical cross section. 


\section{REFERENCES}

Andersen, P.F., J.W. Mercer, and H.O. White, Jr., Numerical modeling of salt-water intrusion at Hallandale, Florida, Ground Water, 26(5), 619-630, 1988.

Ayers, J.F. and H.L. Vacher, Hydrogeology of an atoll island: A conceptual model from detailed study of a Micronesian example, Ground Water, 24(2), 185-198, 1986.

Badon-Ghyben, W., Nota in verband met de voorgenomen put boring nabij Amsterdam. K. Inst. Ing. Tijdschr., The Hague, p. 21, 1889.

Ballance, W.C., Technical Letter: Amchitka-13, Hydraulic Tests in Hole UAe-6H, Amchitka Island, Alaska, U.S.G.S., Federal Center, Denver, CO., 1968.

Ballance, W.C. and G.A. Dinwiddie, Hydraulic Testing of Hole UA-1-HTH-1, Amchitka Island, Alaska, U.S.G.S.-474-144, Federal Center, Denver, CO., 1972.

Bear, J., Some Experiments in Dispersion, J. Geophys. Res., 66(8), 2455-2467, 1961.

Bear, J., Hydraulics of Groundwater, McGraw-Hill, New York, 569 pp., 1979.

Bear, J. and G. Dagan, The transition zone between fresh and salt waters in coastal aquifers, Technion-Israel Institute of Technology Hydraulic Laboratory, Progress Report No. 1, 124pp., 1962.

Bear, J. and D. Todd, The transition zone between fresh and salt waters in coastal aquifers, Hydraulics Laboratory, University of California, Berkeley, Water Resources Center Contribution No. 29, 156 pp., 1960.

Dagan, G., Statistical theory of groundwater flow and transport: Pore to laboratory, laboratory to formation, and formation to regional scale, Water Resour. Res., 22(9S), 120S-134S, 1986.

Elder, J.W., Transient convection in a porous medium, J. Fluid Mech., 27(3), 609-623, 1967.

Fenske, P.R., Event-related hydrology and radionuclide transport at the Cannikin Site, Amchitka Island, Alaska, Center for Water Reources Research, Desert Research Institute, University of Nevada System, NVO-1253-1, 41 pp., 1972.

Frind, E.O., Seawater intrusion in continuous coastal aquifer-aquitard systems, Adv. Water Resources, 5(2), 89-97, 1982.

Gard, L.M. and W.E. Hale, Technical Letter: Long Shot-1: Geology and Hydrology of the Long Shot Site, Amchitka Island, Alaska, U.S.G.S., Federal Center, Denver, CO, 1964.

Gelhar, L.W., Stochastic subsurface hydrology from theory to applications, Water Resour. Res., 22(9S), 135S-145S, 1986.

Glover, R.E., The pattern of fresh water flow in a coastal aquifer, J. Geophys. Res., 64, 439-475, 1959. 
Henry, H.R., Effects of dispersion on salt encroachment in coastal aquifers, Sea Water in Coastal Aquifers, U.S. Geol. Surv. Water Supply Pap. 1613-C, 70-84, 1964a.

Henry, H.R., Interfaces between salt water and fresh water in coastal aquifers, Sea Water in Coastal Aquifers, U.S. Geol. Surv. Water Supply Pap. 1613-C, 35-70, $1964 \mathrm{~b}$.

Herzberg, A., Die Wasserversorgung einiger Nordsee Bader. J. Gasbeleucht. Verw. Beleuchtungsarten Wasserversorg. 44:815-819, 842-844, 1901.

Kashef, A.A.I., Salt-water intrusion in the Nile Delta, Ground Water, 21(2), 160-167, 1983.

Lau, L-K., Dynamic and static studies of seawater intrusion, University of Hawaii Water Resources Research Center, Technical Report No. 3, 31 pp., 1967.

Lee, C-H. and R.T. Cheng, On seawater encroachment in coastal waters, Water Resour. Res., 10(5), 1039-1043, 1974.

Mackay, D.M., D.L. Freyberg, P.V. Roberts, and J.A. Cherry, A natural gradient experiment on solute transport in a sand aquifer, 1. Approach and overview of plume movement, Water Resour. Res., 22(13), 2017-2029, 1986.

Mercado, A., The use of hydrogeochemical patterns in carbonate sand and sandstone aquifers to identify intrusion and flushing of saline water, Ground Water, 23(5), 635-645, 1985.

Peterson, F., J. Williams and S. Wheatcraft, Waste injection into a two-phase flow field: Sand-box and Hele-Shaw model study, Ground Water, 16(6), 410-416, 1978.

Pinder, G.F. and H.H. Cooper, A numerical technique for calculating the position of the saltwater front, Water Resour. Res., 6(3), 875-882, 1970.

Reilly, T.E. and A.S. Goodman, Quantitative analyses of saltwater-freshwater relationships in groundwater systems--a historical perspective, J. Hydrol. 80(1/2), 125-160, 1985.

Sanford, W.E. and L.F. Konikow, A two-constituent solute-transport model for ground water having variable density, U.S. Geological Survey Water-Resources Investigations Report 85-4279, 88pp., 1985.

Segol, G. and G.F. Pinder, Transient simulation of saltwater intrusion in southeastern Florida. Water Resour. Res., 12(1), 65-70, 1976.

Sudicky, E.A., and J.A. Cherry, Field observations of tracer dispersion under natural flow conditions in an unconfined sandy aquifer, Water Pollut. Res. Can., 14, 1-17, 1979.

Sudicky, E.A., J.A. Cherry, and E.O. Frind, Migration of contaminants in groundwater at a landfill: A case study, 4, A natural-gradient dispersion test, J. Hydrol., 63(1/2), 81-108, 1983.

Voss, C.I., A finite-element simulation model for saturated-unsaturated fluid-density-dependent ground-water flow with energy transport or chemically-reactive single-species solute transport, U.S. Geological Survey Water-Resources Investigations Report 84-4369, 409pp., 1984. 
Voss, C.I. and W.R. Souza, Variable density flow and solute transport simulation of regional aquifers containing a narrow freshwater-saltwater transition zone, Water Resour. Res., 23(10), 1851-1866, 1987.

Welty, C. and L.W. Gelhar, Stochastic analysis of the effects of fluid density and viscosity variability on macrodispersion in heterogeneous porous media, Water Resour. Res. 27(8), 2061-2075, 1991.

Welty, C. and L.W. Gelhar, Simulation of large-scale transport of variable density and viscosity fluids using a stochastic mean model, Water Resour. Res., 28(3), 815-827, 1992.

Welty, C., L.W. Gelhar and M.A. Celia, Stochastic analysis of the effects of density and viscosity variability on macrodispersion in heterogeneous porous media. Rept. 321, Ralph M. Parson Lab., Mass. Inst. of Technol., Cambridge, Mass, 344pp., 1989.

Wheatcraft, S.W. and R.W. Buddemeier, Atoll island hydrology, Ground Water, 19(3), 311-320, 1981.

Wheatcraft, S. and F. Peterson, Numerical modeling of liquid waste injection into a two-phase fluid system, University of Hawaii Water Resources Research Center Tech. Rpt. No. 125, 103 pp., 1979. 
APPENDIX A

SALINITY DISTRIBUTIONS FOR 11 SIMULATIONS VARYING THE HYDRAULIC CONDUCTIVITY 


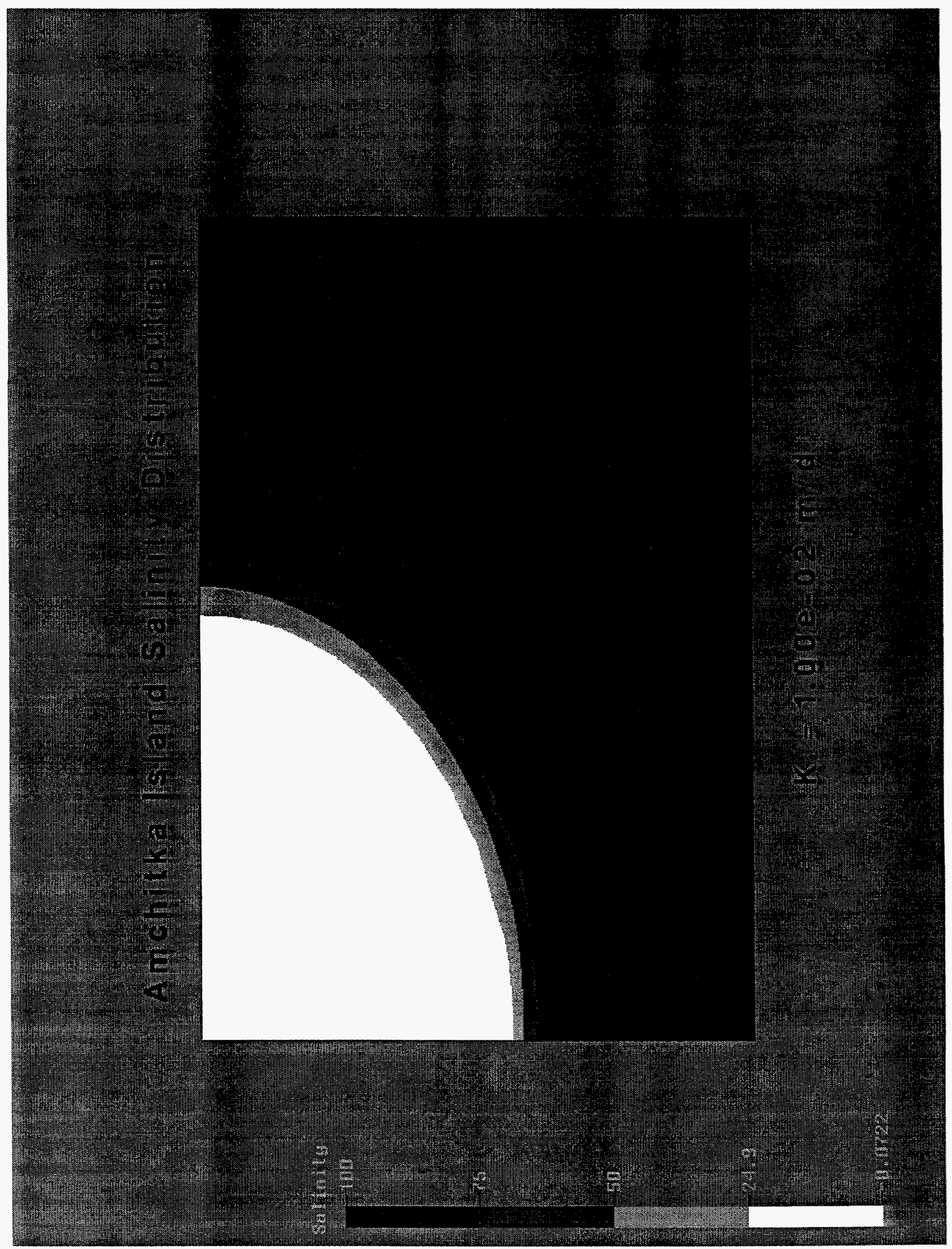

A-2 


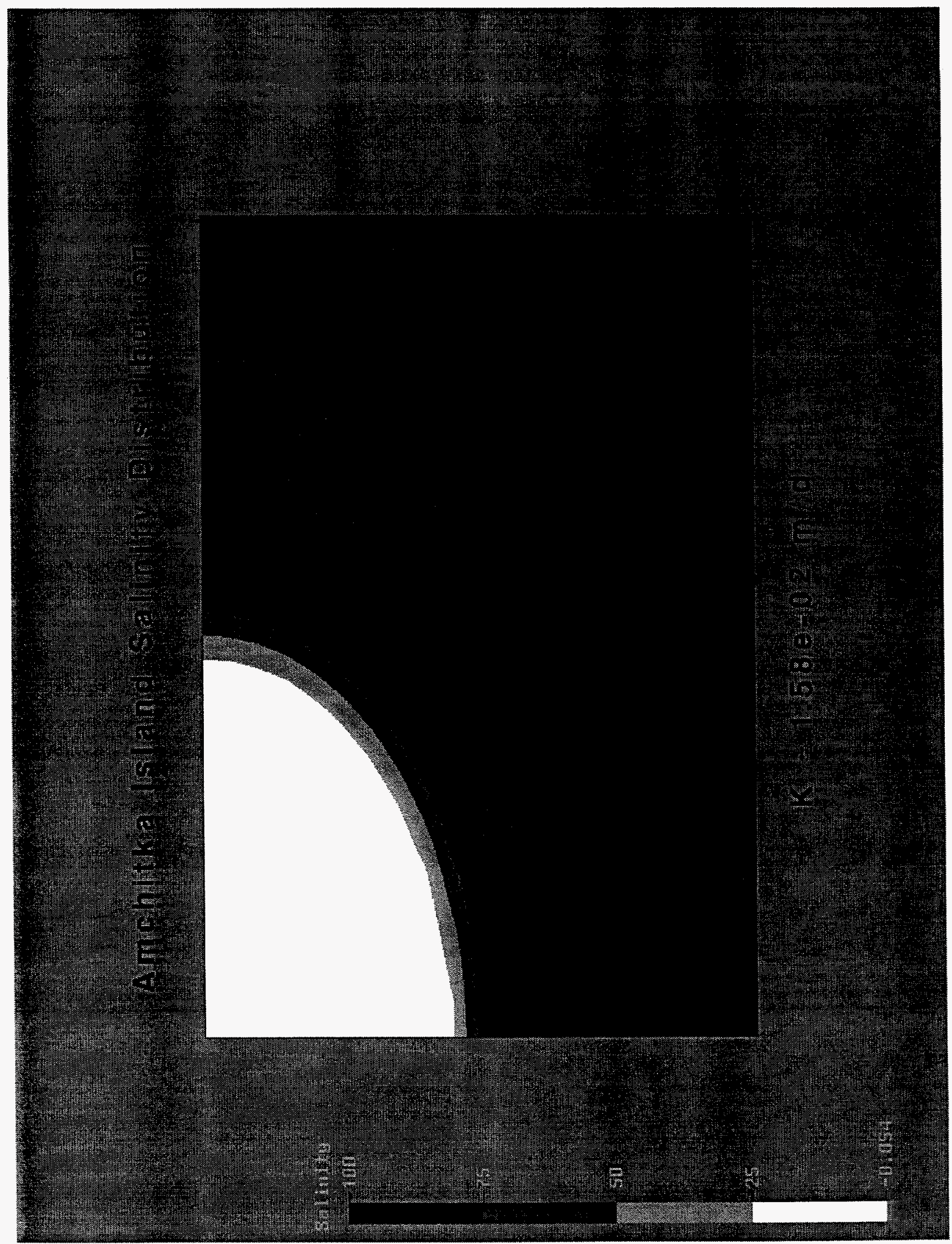

A-3 


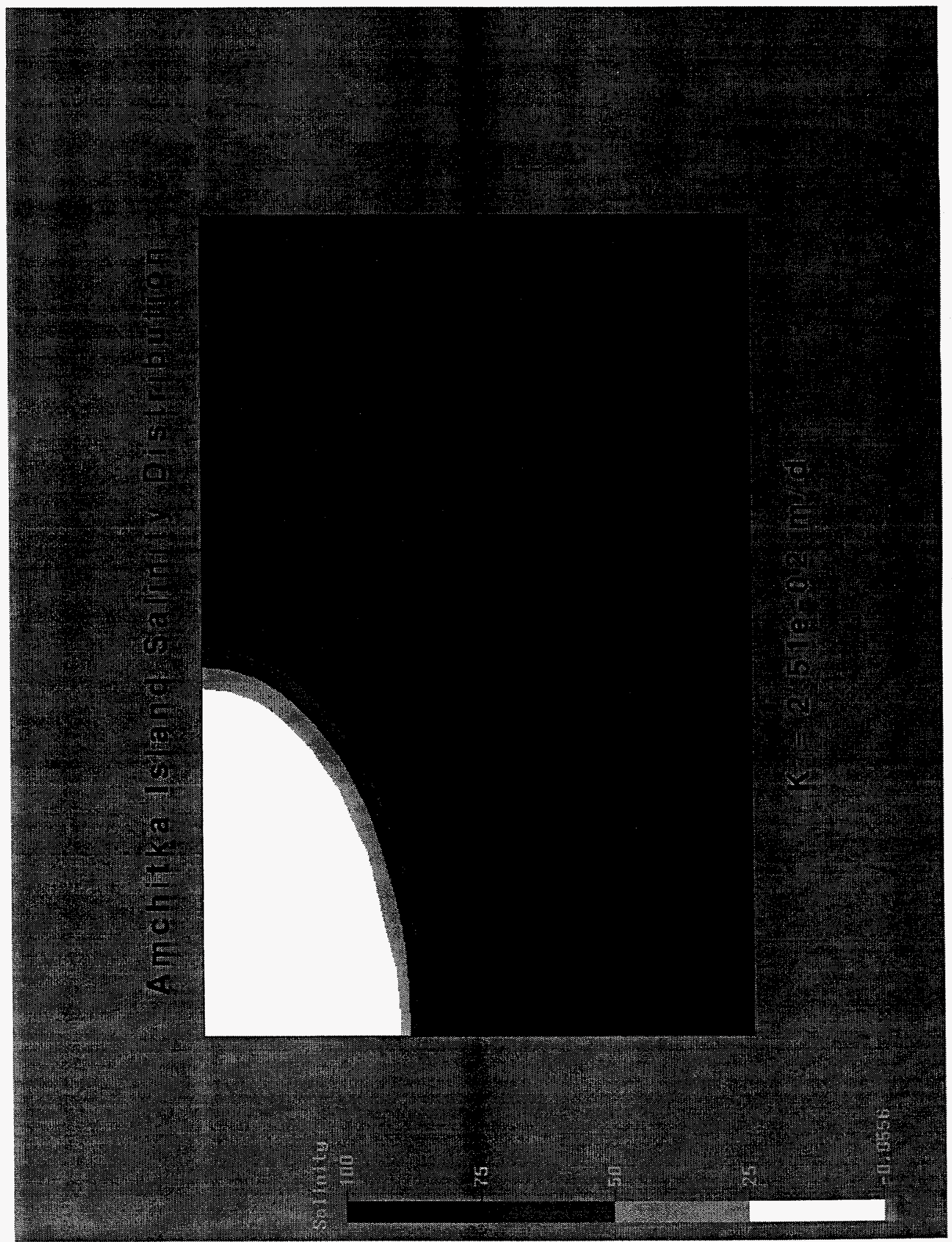

$$
\text { A-4 }
$$




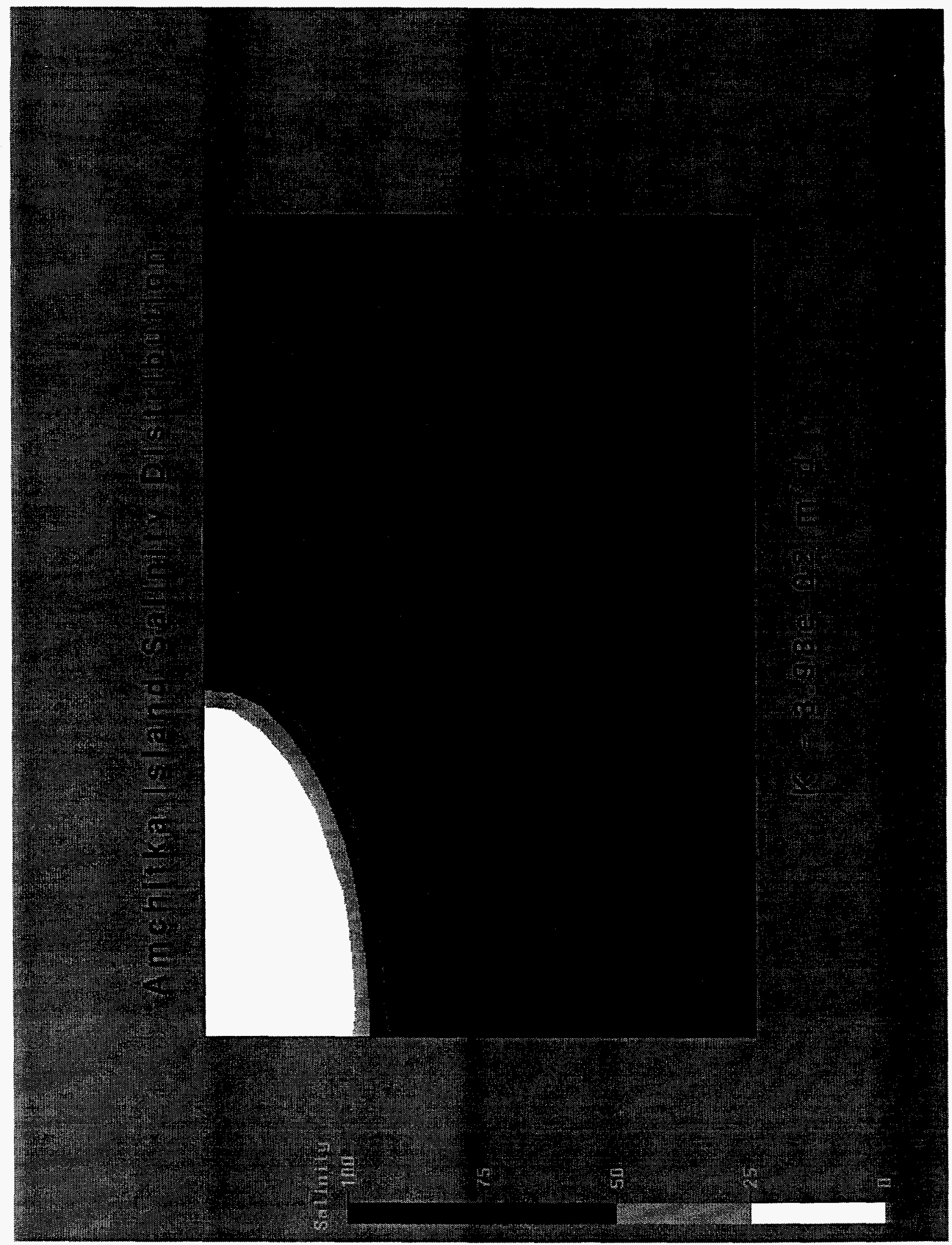

A-5 


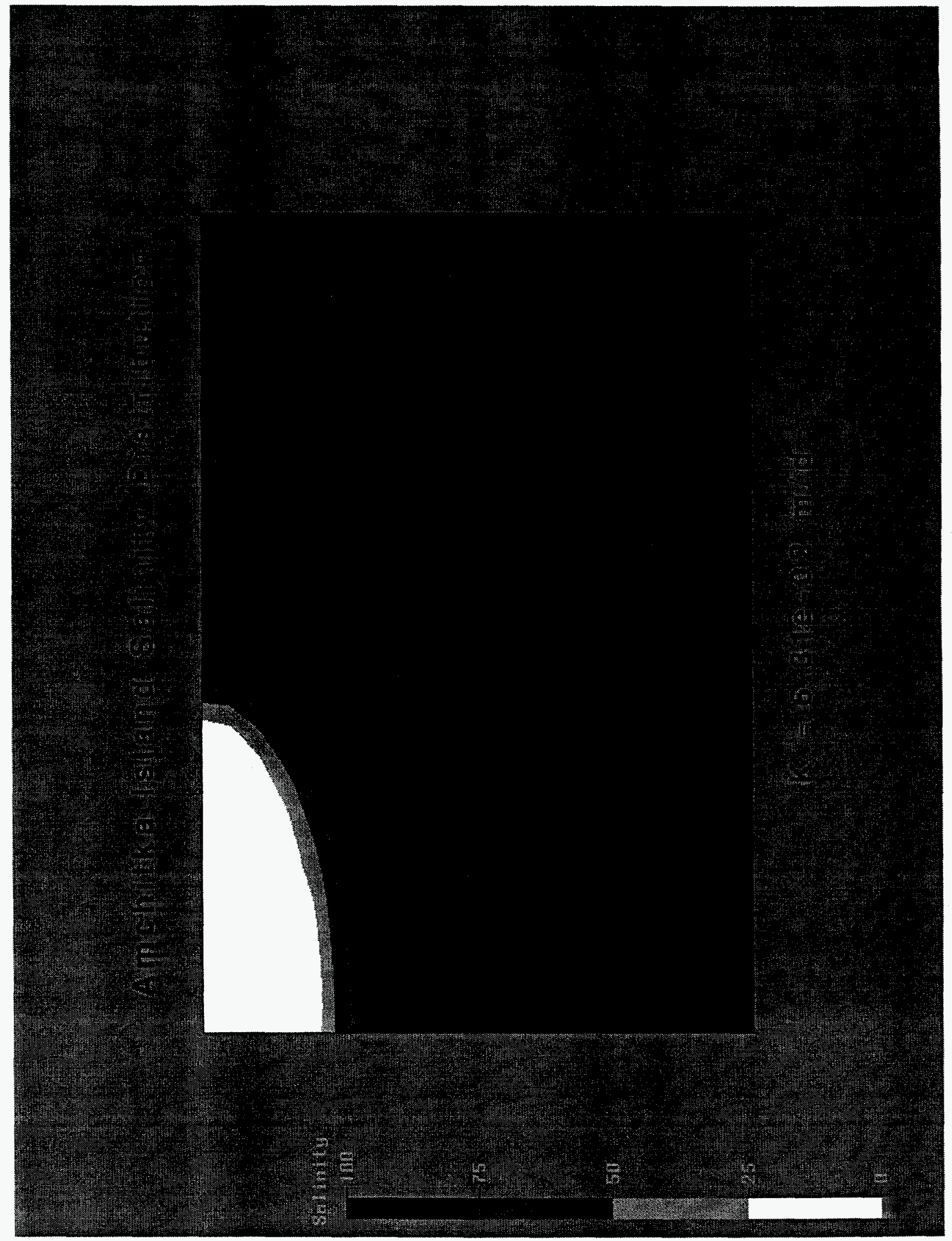

A-6 


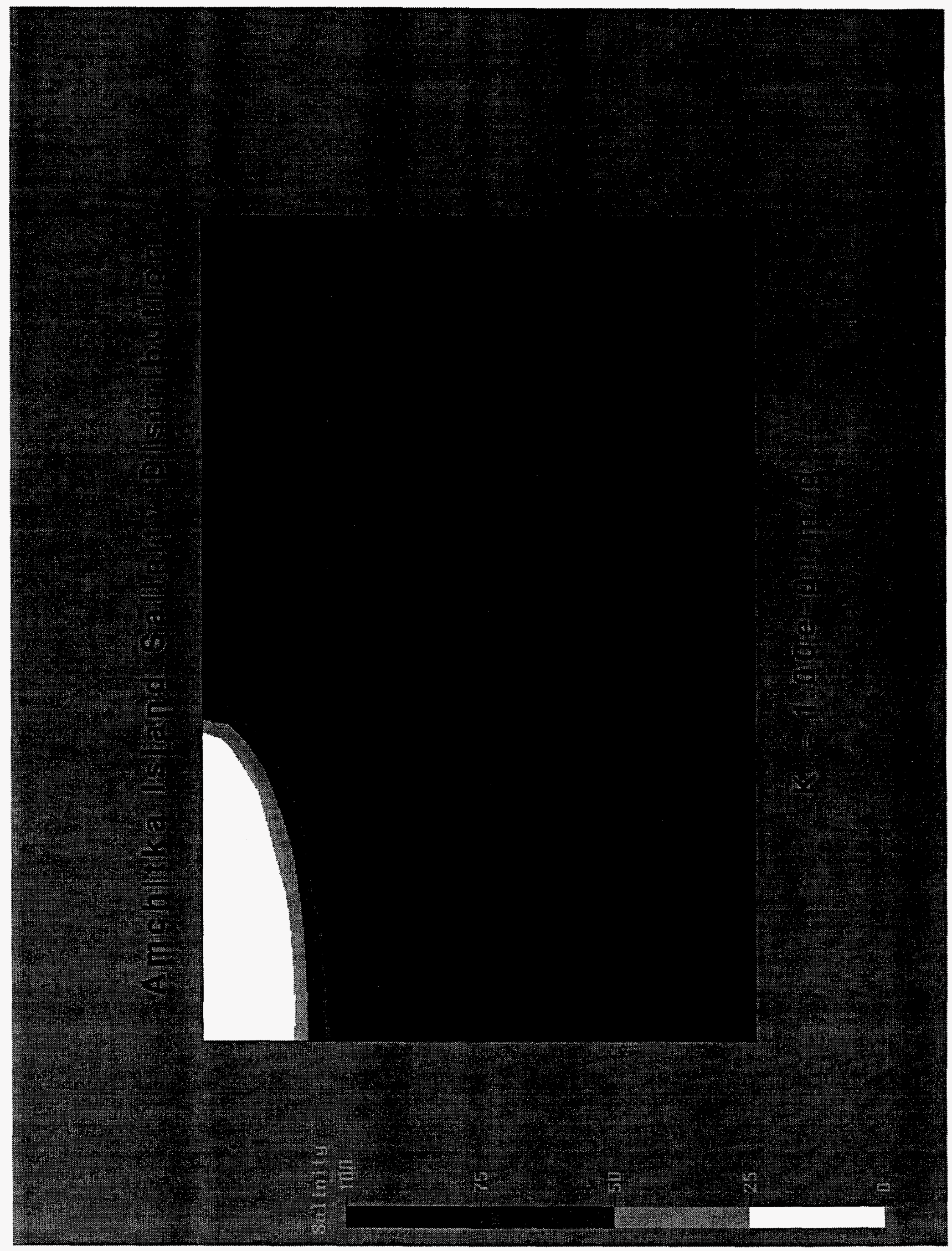

A-7 


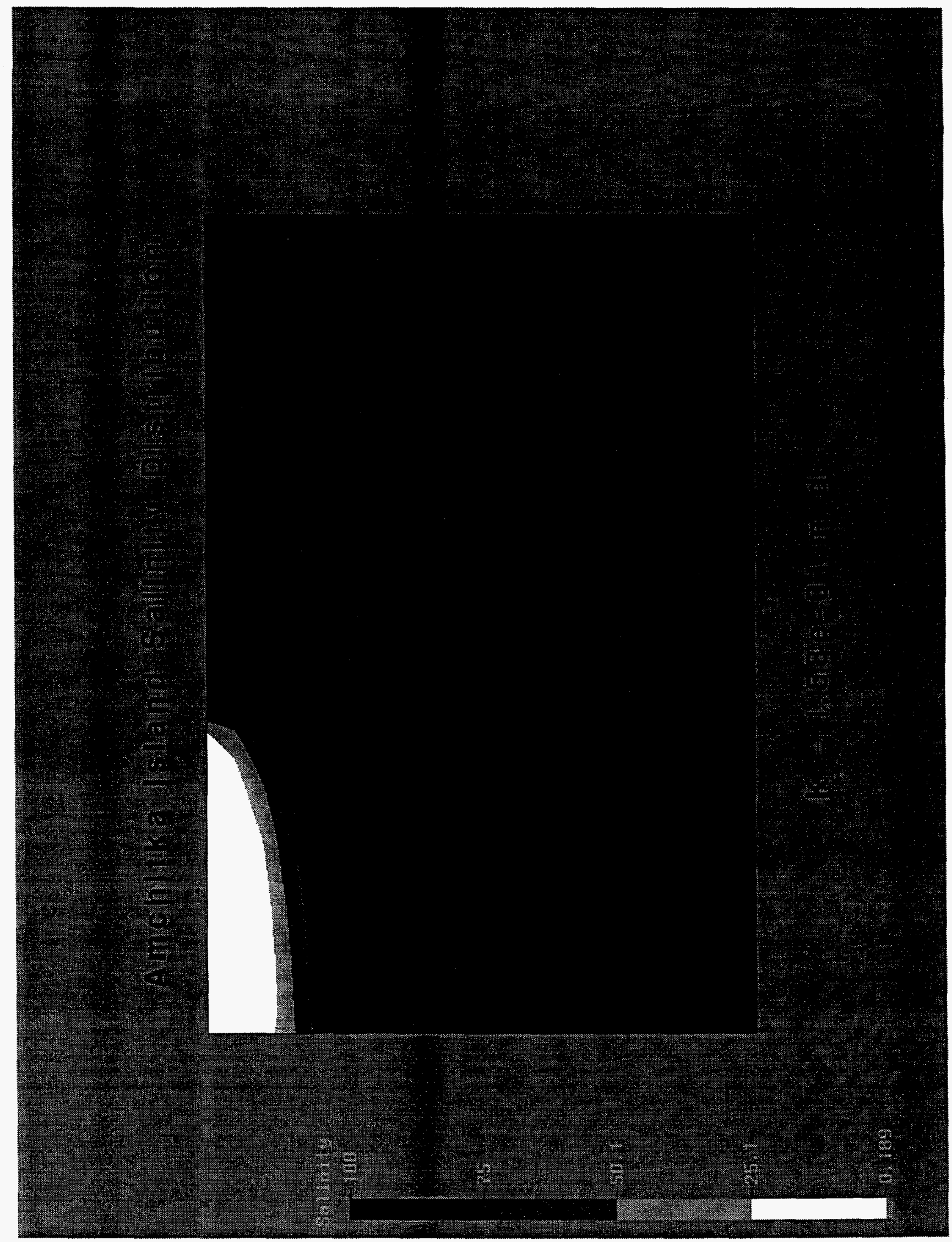

A-8 


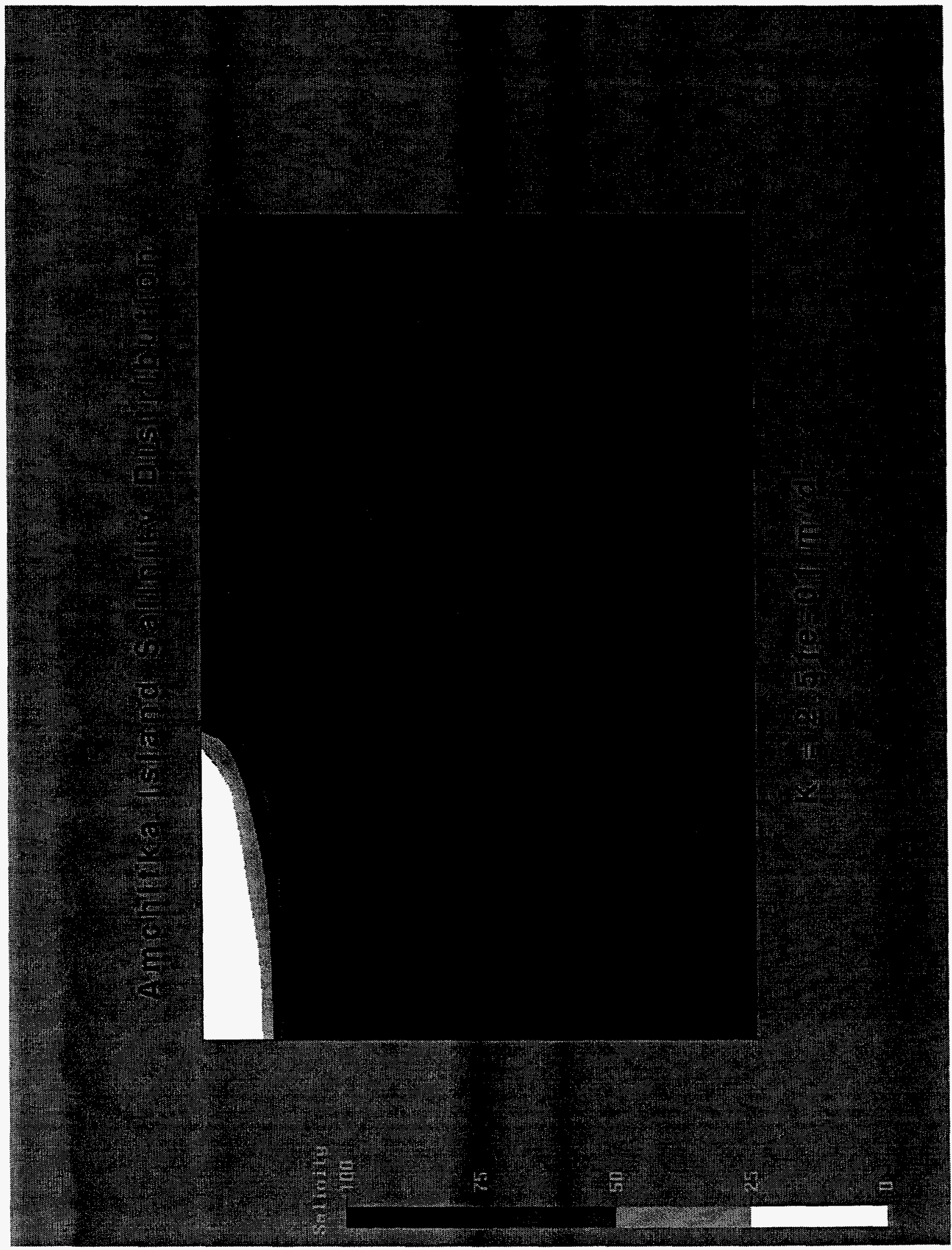

$$
\text { A-9 }
$$




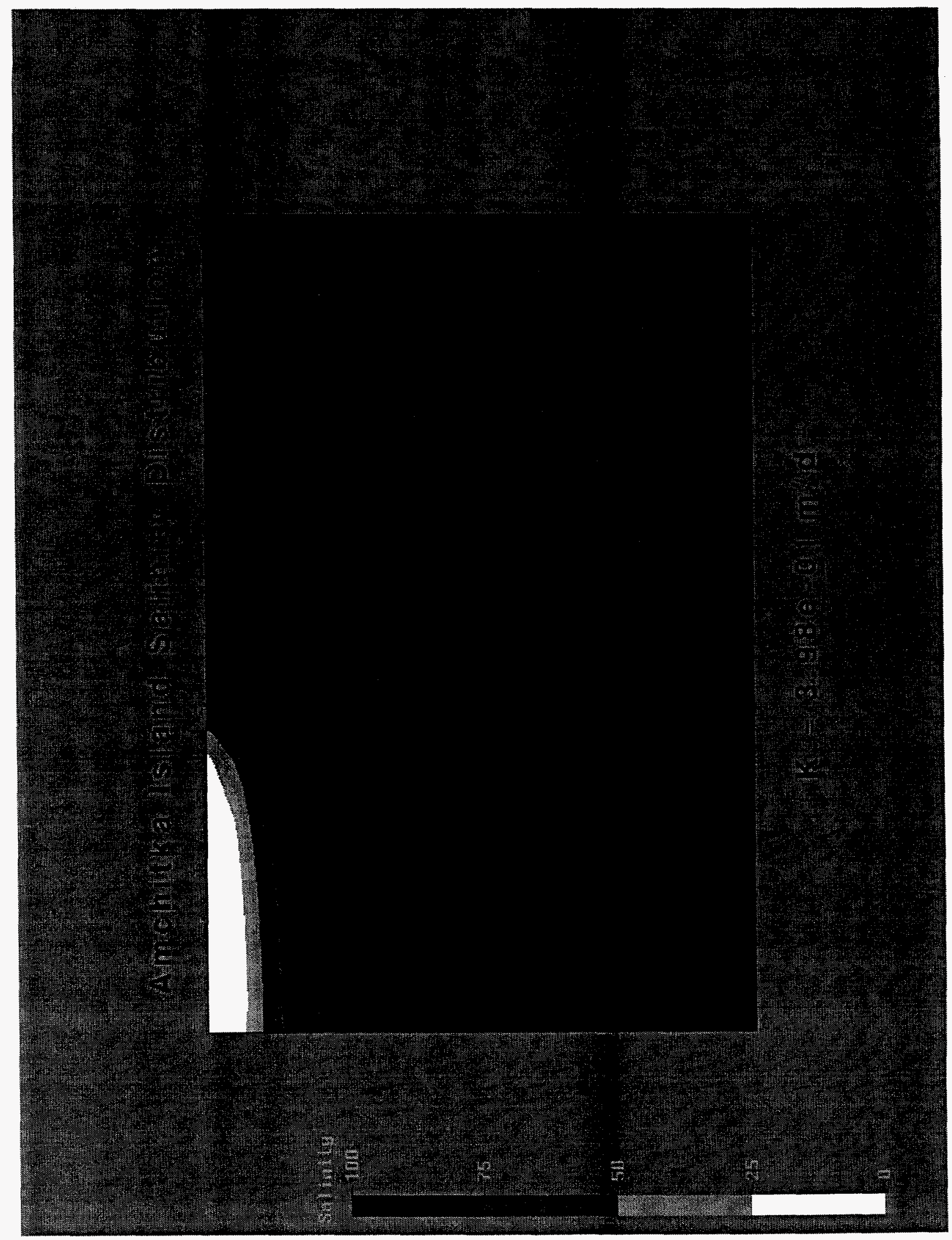

A-10 


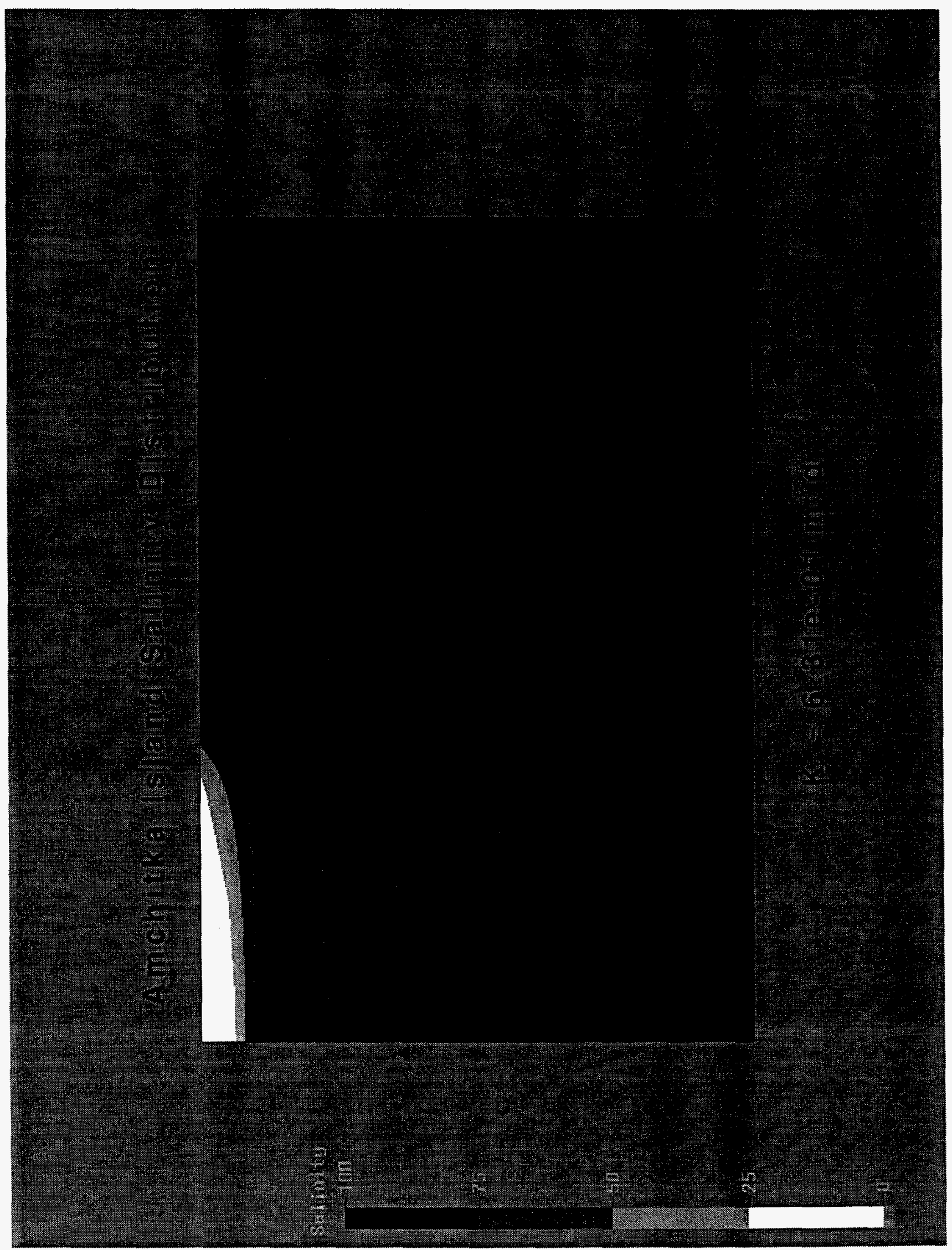

A-11 


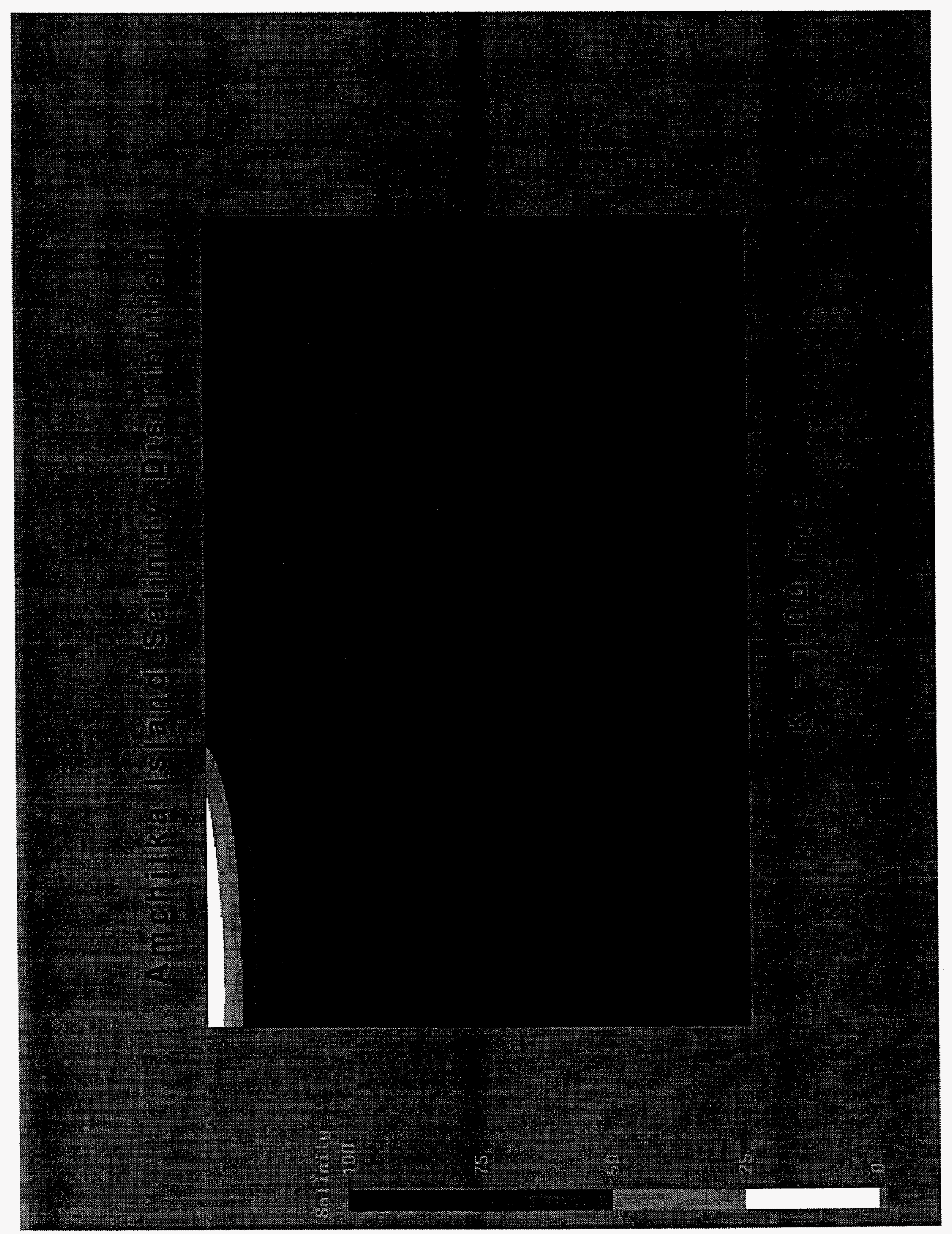

A-12 